\title{
GUÍAS PARA EL TRATAMIENTO DE LA DIABETES MELLITUS TIPO 2. SOCIEDAD ARGENTINA DE DIABETES
}

\section{GUIDELINES FOR THE TREATMENT OF THE DIABETES MELLITUS TYPE 2. ARGENTINE SOCIETY OF DIABETES}

\author{
Coordinadores: María Cristina Faingold, Víctor Commendatore \\ Secretarios: Fabiana Vázquez, Alejandro de Dios
}

\begin{abstract}
Expertos: Claudio González ${ }^{* 1}$, Víctor Commendatore², Julio Bragagnolo ${ }^{3}$, Isaac Sinay ${ }^{4}$, Silvia Lapertosa 5 , Fabiana Vázquez ${ }^{6}$, Carla Musso ${ }^{7}$, Jorge Alvariñas ${ }^{8}$, Alejandro de Dios ${ }^{9}$, Gustavo Frechtel ${ }^{10}$, Susana Salzberg ${ }^{11}$, Alejandro Serra ${ }^{12}$, Cristina Faingold ${ }^{13}$, León Litwak ${ }^{14}$, Juan José Gagliardino ${ }^{15}$, Graciela Fuente ${ }^{16}$, Cristian Suárez Cordo $^{17}$, Alicia Elbert ${ }^{18}$, Carlos Buso ${ }^{19}$, Susana Fuentes ${ }^{20}$
\end{abstract}

\section{RESUMEN}

Objetivos: 1) actualizar la Guía de Tratamiento de la Diabetes Mellitus tipo 2 de la Sociedad Argentina de Diabetes publicada en el año 2010; 2) proveer al equipo de salud una herramienta actualizada para el manejo terapéutico de las personas con esta patología. Materiales y métodos: se convocó a un grupo de expertos, miembros titulares de la Sociedad Argentina de Diabetes, para analizar los trabajos disponibles en distintas fuentes, clasificándolos de acuerdo a su nivel de evidencia (Tabla 2), éste podrá observarse en negrita al final del párrafo correspondiente; sobre esta base se modificó la guía 2010 actualizando sus contenidos. Se designó un comité de redacción responsable de la compaginación final del documento.

Conclusiones: los cambios en el estilo de vida continúan siendo la primera opción terapéutica, la metformina es la droga de primera línea, si no existen contraindicaciones para su uso o intolerancia, cualquiera de las otras familias de fármacos antidiabéticos, la insulina y sus análogos pueden usarse como monoterapia o asociadas entre sí teniendo en cuenta sus contraindicaciones, siempre y cuando no se utilicen juntas aquellas con mecanismos de acción similar. Los algoritmos 1 y 2 pueden considerarse la síntesis de la propuesta actual, elaborada para orientar la toma de decisiones respecto del tratamiento de la DMT2.

Palabras claves: diabetes mellitus tipo 2, guías, tratamiento. Revista de la Sociedad Argentina de Diabetes 2016; Vol. 50 (64-90)

\section{ABSTRACT}

Objectives: 1) update the Guidelines for the Treatment of the Diabetes Mellitus Type 2 of the Argentine Society of Diabetes, published in 2010; 2) provide to the health team updated guidance for the therapeutic management of people with this disease.

Material and methods: a group of experts, full members of the Argentine Society of Diabetes, was convened to analyze the papers available from different sources, classifying them according to their level of evidence (Table 2), written in bold at the end of the paragraph; on this basis the 2010 guideline was modified to update contents. A drafting committee responsible for the final layout of the document was appointed.

Conclusions: changes in lifestyle remain the first therapeutic option, metformin is the drug of first line, if there are no contraindications for use or intolerance, any of the other families of antidiabetic drugs, insulin and insulin analogs, can be used as monotherapy or associated, taking into account their contraindicationsand not using together those with similar action mechanisms. Algorithms 1 and 2 can be considered the synthesis of the current proposal.

Key words: diabetes mellitus type 2, guidelines, treatment. Revista de la Sociedad Argentina de Diabetes 2016; Vol. 50 (64-90)
1* Asesor en la metodología de los procesos de calificación de la evidencia clínica y epidemiológica; Prof. Titular de Farmacología de las Universidades Austral, del Salvador y del Instituto Universitario Cemic; Prof. Titular de Bioestadística y Metodología de la Investigación de la Universidad Católica Argentina, CABA, Argentina

2 Jefe del Servicio de Endocrinología, Diabetes y Nutrición, Hospital San Martín de Paraná, Entre Ríos, Argentina

3 Jefe de la Unidad de Nutrición y Diabetes, Hospital Ramos Mejía, CABA, Argentina

4 Asesor de la Unidad de Diabetes del Instituto Cardiovascular de Buenos Aires, CABA, Argentina

5 Prof. Titular de Nutrición y Educación para la Salud, Facultad de Medicina, Universidad Nacional del Nordeste, Corrientes, Argentina

6 Jefa de Trabajos Prácticos de la Cátedra de Nutrición, Facultad Medicina, Universidad Austral, CABA, Argentina

7 Coordinadora de Diabetes de la Fundación Favaloro, CABA, Argentina
8 Doctor en Medicina, Consultor en Nutrición Hospital E. Tornú, CABA, Argentina

9 Médico de Planta del Servicio de Clínica Médica del Hospital C. Durand, Investigador de la División Genética del Hospital de Clínicas José de San Martín, CABA, Argentina

10 Prof. Asociado a cargo de la Cátedra de Nutrición, Departamento de Medicina (UBA), Jefe de División Genética, Hospital de Clínicas José de San Martín (UBA), Jefe de Nutrición y Diabetes del Hospital Sirio Libanés, CABA, Argentina

11 Directora del Departamento de Investigaciones Clínicas del Instituto Centenario, CABA, Argentina

12 Prof. Titular de Farmacología, Facultad de Ciencias Médicas (UCA), Prof. Regular Adjunto de Farmacología, Facultad de Medicina (UBA), CABA, Argentina

13 Responsable Médico del Servicio de Endocrinología de la Unidad Asistencial Dr. César Milstein, Médica de Planta del Instituto Cardiovascular de Buenos Aires, Directora de la Carrera de Médico Especialista en Endocrinología (UBA), CABA, Argentina 
14 Ex Jefe y actual Médico Asociado de la Sección Diabetes del Servicio de Endocrinología, Metabolismo y Medicina Nuclear del Hospital Italiano de Buenos Aires, Docente del Instituto Universitario del Hospital Italiano, CABA, Argentina

15 Investigador Superior del CONICET, Centro de Endocrinología Experimental y Aplicada (CENEXA), UNLP-CONICET, Prov. de Bs. As., Argentina

16 Jefa de la Unidad de Nutrición del Hospital C. Durand, CABA, Argentina

Contacto del autor: Víctor Commendatore/

María Cristina Faingold

E-mail: v.commenda@gmail.com/mfaingold@intramed.net Correspondencia: Urreaga 1256 (CP 3100), Paraná, Entre
17 Coordinador del Programa de Diabetes de la Municipalidad de San Martín y de la Unidad de Diabetes del Hospital Diego Thompson, San Martín, Prov. de Bs. As., Argentina

18 Directora del Centro de Enfermedades Renales e Hipertensión Arterial, CABA, Argentina

19 Médico de Planta del Hospital Municipal de Oncología Marie Curie, CABA, Argentina

20 Integrante del equipo de Cirugía Bariátrica y Metabólica del Hospital El Cruce, Florencio Varela, Prov. de Bs. As., Argentina

Ríos, Argentina/ La Rioja 951, (C1221ACl), CABA, Argentina Tel.: (011) 154177168/ (011) 4959-1500

Fecha de trabajo recibido: 20/06/2016

Fecha de trabajo aceptado: 05/09/2016
Conflictos de interés: no presentan conflictos de interés con el tema de estas recomendaciones y su publicación: Víctor Commendatore, Julio Bragagnolo, Carla Musso, Susana Salzberg, Juan José Gagliardino, Cristian Suárez Cordo y Alicia Elbert.

Claudio González: Director Médico de MSD Argentina. Isaac Sinay: recibió honorarios por actividad docente, asesorías y colaboración en áreas de investigación de los laboratorios Merck, Novartis, AstraZeneca, Boehringer Ingelheim, Janssen, GlaxoSmiteKline, Eli Lilly, Sanofi Aventis, Novo Nordisk y Servier. Silvia Lapertosa: recibió honorarios por actividad docente de los laboratorios Boehringer Ingelheim, Novo Nordisk, Sanofi, Merck, Montpellier y AstraZeneca. Fabiana Vázquez: recibió honorarios por actividad docente de los laboratorios Novo Nordisk, Boehringer Ingelheim, AstraZeneca, Servier e Investi. Jorge Alvariñas: recibió honorarios de los laboratorios Craveri, Novo Nordisk, AstraZeneca, Sanofi, Merck. Alejandro de Dios: recibió honorarios por actividad docente del laboratorio AstraZeneca. Gustavo Frechetel: recibió honorarios de los laboratorios Sanofi Aventis, Eli Lilly, Novo Nordisk, Merck, AstraZeneca, GlaxoSmiteKline. Alejandro Serra: asesor médico de Química Montpellier S.A. Cristina Faingold: miembro del consejo asesor y disertante de los laboratorios Novo Nordisk, Sanofi y AstraZeneca. León Litwak: participó en protocolos de investigación farmacológica y disertante de los laboratorios Eli Lilly, AstraZeneca, Sanofi, MSD, Novo Nordisk, disertante de Ios laboratorios Abbott, Craveri y Medtronic. Graciela Fuente: asesora y disertante de los laboratorios Abbott, AstraZeneca, Craveri, Eli Lilly, MSD y Novo Nordisk. Carlos Buso: ha sido disertante de los laboratorios AstraZeneca, Novo Nordisk, MSD, Francelab, Química Montpellier, Gador y Roche Diagnóstica. Susana Fuentes: ha sido disertante de los laboratorios Eli Lilly, Novartis, Química Montpellier, Jonshon \& Jonshon y Covidean.

\section{INTRODUCCIÓN OBJETIVOS METODOLOGÍA \\ CAMBIOS EN EL ESTILO DE VIDA}

- Plan de alimentación

- Actividad física y/o ejercicio

DROGAS PARA ELTRATAMIENTO DE LA DMT2

- Generalidades

- Metformina

- Tiazolidindionas

- Sulfonilureas

- Meglitinidas

- Inhibidores de la $\alpha$-glucosidasa

- Agonistas del receptor de glucagón-like peptide 1 (aGLP-1)

- Inhibidores de la DPP-4 (iDPP-4)

- Inhibidores del co-transportador de sodio 7 glucosa tipo 2 (iSGLT-2)

- Tratamiento farmacológico de la obesidad en pacientes con DMT2

\section{INSULINOTERAPIA EN LA DMT2 CIRUGÍA BARIÁTRICA ALGORITMO DETRATAMIENTO PARA LA DMT2 BIBLIOGRAFÍA}

\section{INTRODUCCIÓN}

La diabetes mellitus tipo 2 (DMT2) se diagnostica frecuentemente en forma tardía, entre el 24 y el $50 \%$ de las personas desconocen que la padecen, y dicha proporción aumenta marcadamente en zonas rurales'. Frecuentemente los pacientes ya poseen complicaciones al momento del diagnóstico; del 16 al $21 \%$ pueden presentar retinopatía, del 12 al 23\% nefropatía y del 25 al $40 \%$ neuropatía, estando dentro de los 10 primeros lugares como causa de consulta y de mortalidad en la población adulta².

En ocasión de la publicación del último Atlas de la Federación Internacional de Diabetes (IDF, su siglas en inglés) y haciendo referencia a las clases sociales afectadas, su presidente puntualizó: "Un $80 \%$ de las personas con diabetes vive en países de ingresos medios y bajos, y los socialmente menos afortunados de cualquier país son los más vulnerables a la enfermedad"3.

Las distintas regiones están siendo afectadas con diferentes niveles de compromiso. La Tabla 1 muestra la prevalencia actual y las estimaciones para 2035 publicadas por IDF . 


\begin{tabular}{|l|c|c|c|}
\hline $\begin{array}{l}\text { Región de la } \\
\text { FID }\end{array}$ & $\begin{array}{l}\text { Año 2013 } \\
\text { en millones }\end{array}$ & $\begin{array}{l}\text { Año 2013 } \\
\text { en millones }\end{array}$ & $\begin{array}{c}\text { Aumento } \\
\text { en \% }\end{array}$ \\
\hline África & 19,8 & 41,4 & 109 \\
\hline $\begin{array}{l}\text { Medio Oriente } \\
\text { y Norte de } \\
\text { África }\end{array}$ & 34,6 & 67,9 & 96 \\
\hline $\begin{array}{l}\text { Sudoeste } \\
\text { Asiático }\end{array}$ & 72,1 & 12,3 & 71 \\
\hline $\begin{array}{l}\text { América Central } \\
\text { y del Sur }\end{array}$ & 24,1 & 38,5 & 60 \\
\hline $\begin{array}{l}\text { Pacífico } \\
\text { Occidental }\end{array}$ & 138,2 & 201,8 & 46 \\
\hline $\begin{array}{l}\text { América del } \\
\text { Norte y Caribe }\end{array}$ & 36,7 & 50,4 & 37 \\
\hline Europa & 56,3 & 68,9 & 22 \\
\hline Mundo & 381,8 & 591,9 & 55 \\
\hline
\end{tabular}

Tabla 1: Prevalencia actual y estimaciones para el año 2035 publicadas por IDF.

El área de América Central y del Sur incluye 20 países con más de 500 millones de habitantes; en esta región existen 24,1 millones de personas con diabetes y las proyecciones para el año 2035 estiman que la cifra alcanzará los 38,5 millones, lo que indica un incremento esperado de aproximadamente el $60 \%$, ubicando a nuestra región entre las cuatro con mayor tasa de crecimiento ${ }^{4}$.

Este comportamiento epidemiológico se relaciona con diversos factores, entre los cuales se destacan la etnia, el cambio en los hábitos de vida, la obesidad, el envejecimiento de la población y el aumento de la expectativa de vida. Su prevalencia varía de acuerdo a si es zona urbana, oscilando en este caso entre el 7 y el $8 \%$, o rural con apenas del 1 al $2 \%$,6.

En nuestro país, las Encuestas Nacionales sobre Factores de Riesgo para Enfermedades Crónicas No Transmisibles, realizadas los años 2005, 2009 y 2013 son una fuente importante de información. En ellas se estudiaron personas mayores de 18 años por medio de un proyecto validado de OMS/OPS, mediante una muestra probabilística de hogares, representativa de la población general del país con metodología encuestal.

Allí se encontró que la prevalencia de DM fue del 8,4\% (IC $95 \%$ : 7,8-9,1), 9,6\% (IC 95\%: 9,110,1 ) y $9,8 \%$ (IC $95 \%: 9,3-10,3$ ) respectivamente, y la de obesidad del 14,6\% (IC 95\%: 7,9-9,1), 18\% (IC 95\%: 17,4-18,7) y $20,8 \%$ (IC 95\%: 19,9-21,8). Esto demuestra un incremento de la prevalencia de DM del $14,3 \%$ en el primer período y del $28,6 \%$ en el segundo, y de obesidad del 2,1 y del $5,5 \%$ respectivamente ${ }^{7,8,9}$.

Los estudios sobre costos han demostrado que las internaciones representan el mayor gasto de atención en las personas con diabetes y que esa erogación puede aumentar en relación con el desarrollo y la progresión de las complicaciones crónicas, en especial las macrovasculares, alcanzando su máxima expresión cuando además se agregan las complicaciones microvasculares ${ }^{10,11}$.

Las personas con DMT2 constituyen un grupo poblacional heterogéneo por lo cual es imprescindible individualizar las estrategias terapéuticas con la finalidad de alcanzar los objetivos del tratamiento. Es así que objetivos más estrictos buscando glucemias cercanas a valores normales puede constituir la meta en aquellas personas en las que el logro de esos niveles resulte favorable en la ecuación riesgo/beneficio.

La DMT2 es un trastorno metabólico complejo; su etiopatogenia resulta de la coexistencia de defectos multiorgánicos que incluyen insulinorresistencia en el músculo y el tejido adiposo, un deterioro progresivo de la función y la masa de células- $\beta$ pancreáticas, el aumento de la producción hepática de glucosa, la secreción inadecuada de glucagón, la disminución de la producción de incretinas y otras alteraciones hormonales.

La insulinorresistencia está influenciada por factores genéticos y ambientales y reconoce como condición subyacente la gran prevalencia de obesidad, a su vez ligada estrechamente a la alimentación hipercalórica y al sedentarismo. En la medida en que la insulinorresistencia empeora, el páncreas -para mantener la glucemia dentro de la normalidad- compensa aumentando la secreción de insulina; con la evolución de la enfermedad la capacidad secretoria pancreática claudica deteriorándose la homeostasis de la glucosa.

El número de fármacos y estrategias desarrolladas en los últimos años para el tratamiento de la DMT2 obliga al equipo de salud a considerar diversos factores para la elección terapéutica y la toma de decisiones: severidad de la hiperglucemia, antigüedad presunta de la enfermedad, presencia de comorbilidades y de complicaciones crónicas, riesgo de hipoglucemia, efectos colaterales, costos, posibilidad de adhesión y preferencias del paciente.

Se debe enfatizar que los cambios en el estilo de vida, basados en una alimentación adecuada y en la actividad física reglada, deberán ser instituidos previamente al inicio de cualquier fármaco, debiéndose reforzar su trascendencia en cada consulta. En los 
casos de reciente diagnóstico, con un compromiso metabólico moderado cuando los cambios en el estilo de vida no alcanzan para lograr los objetivos de control glucémico, se deberá iniciar el tratamiento con fármacos debidamente seleccionados.

En situaciones de hiperglucemia sostenida o ante la presencia de síntomas clínicos determinados por ésta, se considerarán -de acuerdo a la severidad del caso- las siguientes alternativas terapéuticas:

- Indicar fármacos antidiabéticos (ADs) en la primera consulta.

- Iniciar el tratamiento con insulina basal, combinada o no con otros ADs.

- Considerar el inicio de un tratamiento intensificado, con insulina basal y correcciones con insulinas de acción rápida o ultra rápida.

Cualquiera sea la estrategia seleccionada, dentro de un período de tres a seis meses se deberá evaluar a través de la determinación de la HbA1c si se ha alcanzado el objetivo de control.

\section{OBJETIVOS}

1) Actualizar la Guía de Tratamiento de la Diabetes Mellitus Tipo 2 de la Sociedad Argentina de Diabetes publicada en el año 2010.

2) Proveer al equipo de salud una herramienta actualizada para el manejo terapéutico de las personas con esta patología.

Dada la diversidad y complejidad del tratamiento es esencial el diseño de guías basadas en las evidencias clínicas para que los médicos clínicos, generalistas, internistas, de familia y especializados traten de forma eficaz y segura a estos pacientes. En el año 2010 se publicaron las Guías de Tratamiento de la Diabetes Mellitus Tipo 2 (DMT2) de la Sociedad Argentina de Diabetes, habiendo sido elaboradas por un grupo de expertos convocados a tal objeto $\left({ }^{*}\right)$. Por la necesidad de actualización, fundamentalmente en relación a los avances respecto del tratamiento, se confeccionó el presente documento sobre la base del anterior y se actualizó la información considerando los nuevos trabajos publicados.

\section{METODOLOGÍA}

Para su actualización se convocó a un Grupo de Expertos integrado por médicos nutricionistas, endocrinólogos y clínicos, todos miembros titulares de la Sociedad Argentina de Diabetes, quienes analizaron la literatura disponible en distintas fuentes y la clasificaron de acuerdo con su nivel de evidencia, la que se encuentra en negrita al final del párrafo correspondiente (Tabla 2). Posteriormente se designó un comité de redacción para la compaginación del documento final.

\begin{tabular}{|l|l|}
\hline $\begin{array}{l}\text { Nivel de } \\
\text { evidencia }\end{array}$ & Tipos de estudio \\
\hline A & $\begin{array}{l}\text { - ECC correctamente aleatorizado con un control } \\
\text { explícito del error alfa y un poder suficiente } \\
\text { - Metaanálisis de buena calidad }\end{array}$ \\
\hline B & $\begin{array}{l}\text { - ECC correctamente aleatorizado pero sin un con- } \\
\text { trol explícito del error alfa y/o que no alcanza un } \\
\text { poder suficiente para probar en forma inequívoca } \\
\text { la efectividad de una intervención } \\
\text { Análisis de subgrupos y post hoc de ECC que no } \\
\text { alcanza un poder suficiente para probar en forma } \\
\text { inequívoca la efectividad de una intervención } \\
\text { Revisión sistemática } \\
\text { - Informe del comité de expertos con metodología } \\
\text { explícita }\end{array}$ \\
\hline C & $\begin{array}{l}\text { ECC sin una correcta aleatorización } \\
\text { - Estudios de cohorte }\end{array}$ \\
\hline D & $\begin{array}{l}\text { : Series de antes y después } \\
\text { Estudio de cohorte histórica } \\
\text { - Estudio de caso-control }\end{array}$ \\
\hline Otros (E) & $\begin{array}{l}\text { - Series de antes y después } \\
\text { Estudio de cohorte histórica } \\
\text { - Estudio de caso-control }\end{array}$ \\
\hline ECC: Experimento clínico controlado. \\
\hline
\end{tabular}

Tabla 2: Niveles de evidencia utilizados en el documento.

\section{CAMBIOS EN EL ESTILO DE VIDA - Plan de alimentación}

La terapia nutricional es una parte fundamental del tratamiento integral y del auto-cuidado de la DM. Los objetivos de la terapia nutricional del paciente diabético son:

1) Mantener o mejorar la calidad de vida y la salud metabólica y nutricional.

2) Prevenir y tratar las complicaciones agudas y crónicas de la enfermedad.

(*) Guía de Tratamiento de la Diabetes Mellitus Tipo 2 de la Sociedad Argentina de Diabetes 2010. Coordinadores: Gustavo Frechtel y León Litwak. Secretarios: María Cristina Faingold y Víctor Commendatore. Revisor: José Costa Gil. Expertos: Jorge Alvariñas, Pablo Arias, Julio Bragagnolo, Guillermo Burlando, Ana Lía Cagide, Lina Capurro, Víctor Commendatore, Guillermo Dieuzeide, Luis De Loredo, Rubén de Marco, María Cristina Faingold, Gustavo Frechtel, Norma Ferrari, Graciela Fuente, Juan Gagliardino, Alicia García Albarracín, Claudio González, Luis Grosembacher, Silvia Lapertosa, Astrid Libman, León Litwak, María Amelia Linari, Pedro Lobo, Manuel Martí, Carla Musso, Félix M. Puchulu, Martín Rodríguez, Silvia Saavedra, Martha de Sereday, Isaac Sinay, Pedro Tesone, Mercedes Traversa, Gloria Viñes y Jorge Waitman. 
3) Tratar las comorbilidades y los trastornos asociados.

La terapia nutricional puede reducir la hemoglobina glicosilada A1c (HbA1c) en un 0,8 a 2,0\%, proporción que es igual o mayor a la obtenida con el uso de algunos fármacos antidiabéticos (ADs); este efecto se acentúa cuando se emplea con otras estrategias en el cuidado de la DM, como cambios en el estilo de vida $(C E V)^{12,13}$.

Se estima que el $80 \%$ de la población con DMT2 tiene sobrepeso u obesidad, siendo el riesgo de muerte por todas las causas, las cardiovasculares y algunas formas de cáncer, aumentando con el excesivo contenido de grasa corporal, predominantemente abdominal.

La pérdida de peso incrementa la sensibilidad a la insulina, mejora la captación periférica de glucosa y disminuye su producción hepática, con lo que desciende la glucemia en ayunas y en el período prandial; por ello la pérdida de peso es un objetivo terapéutico importante para individuos con DM más sobrepeso u obesidad ${ }^{14,15}$.

Un problema adicional para el cumplimiento del plan de alimentación es el nivel de adhesión del paciente a la prescripción, en este sentido, el trabajo del equipo de salud (médico, nutricionista-dietista o Lic. en Nutrición, educador en diabetes) suele jugar un papel destacado en la educación, el entrenamiento, la motivación y el reforzamiento para el cumplimiento y sostén de las indicaciones en el tiempo. La educación nutricional es igualmente efectiva en forma grupal o individual $(\mathbf{B})^{16}$ habiéndose demostrado la eficacia de estas medidas para lograr cambios duraderos en la alimentación $(\mathbf{A})^{17 .}$

Las personas con diabetes deben seguir un plan de alimentación individualizado para ajustarse a la edad, necesidades biológicas, a patologías concomitantes, cultura, estilo de vida, posibilidades económicas, actividad habitual y preferencias personales $^{18}$. Esto incluye consumo de alimentos variados de los cinco grupos principales (vegetales y frutas, cereales, leche y derivados, carnes, aceites y azúcares), asegurando un adecuado ingreso de carbohidratos, proteínas, ácidos grasos esenciales, vitaminas, minerales y fibra dietaria ${ }^{19}$.

Se denomina fibra a los compuestos de origen vegetal constituidos por macromoléculas no digeribles, debido a que las enzimas del intestino no pueden hidrolizarlas; se clasifica según el grado de solubilidad en: a) Fibras insolubles: las que forman con el agua mezclas de baja viscosidad; dentro de éstas se encuentran la celulosa, la mayoría de las hemicelulosas y la lignina. Los cereales son especialmente ricos en fibras insolubles, como ejemplo podemos citar el salvado de trigo.

b) Fibras solubles: las que forman mezclas de consistencia viscosa, su grado de viscosidad depende del vegetal o fruta utilizado; dentro de éstas se encuentra la pectina, presente en frutas y vegetales como naranja, manzana, zanahoria, hojuelas del salvado de avena, cebada y legumbres.

La fibra soluble mejora más el control de la glucosa en sangre que las insolubles; los posibles factores implicados son el retraso del vaciamiento gástrico y el atrapamiento de los carbohidratos, por lo que se reduciría su absorción y por lo tanto el nivel de glucemia.

\section{Fórmula sintética}

1. Valor calórico total (VCT): necesario para lograr un correcto estado nutricional.

2. Hidratos de carbono: $50-55 \%$ del VCT, en lo posible aquellos presentes en alimentos con bajo índice y carga glucémica, como los ricos en fibras solubles e insolubles.

3. Proteínas: $1 \mathrm{~g} / \mathrm{kg}$ de peso teórico/día ó 1015\% del VCT.

4. Grasas: 30 a $35 \%$ del VCT (como en la población general) cuya distribución debe ser:

- Menos del 7\% de grasas saturadas.

- Menos del 10\% de grasas poliinsaturadas, intentando lograr una relación entre omega 3 y omega 6 de 4 ó 5 a 1, incrementando el consumo de pescados de agua fría. El uso de aceites de pescado en las comidas de las personas con DMT2 (3-18 g/día) disminuye el nivel de triglicéridos e incrementa el c-HDL.

- Completar con grasas monoinsaturadas.

- Disminuir a menos del 1\% los ácidos grasos trans presentes en las margarinas, frituras, galletas dulces y saladas hechas con aceite vegetal, etc. ${ }^{20,21,22,23}$.

5. Fibra: más de $25 \mathrm{~g} /$ día, teniendo en cuenta un aporte de 10 a $13 \mathrm{~g}$ cada $1.000 \mathrm{cal}$, siendo de 25 g cada 2.000 calorías.

Los alimentos deberían tener un índice "gramo:caloría" elevado para aumentar la saciedad, desalentar el sobreconsumo y lograr un peso saludable; se prefiere alcanzar dicha relación con el plan alimentario, de esta manera se produce un 
mejor efecto metabólico. De no lograrse, pueden utilizarse suplementos de fibra ${ }^{24,25}$.

\section{Edulcorantes}

Los siguientes edulcorantes han sido aprobados por la Administración de Drogas y Alimentos (FDA, su sigla en inglés): acesulfame K (potásico), aspartame, sacarina, neotame y sucralosa. La agencia Health de Canadá, la Agencia Europea de Medicamentos (EMA, su sigla en inglés) y la Administración Nacional de Medicamentos, Alimentos y Tecnología Médica (ANMAT) en nuestro país han aprobado además los ciclamatos. Todos han mostrado seguridad cuando se usan en personas con diabetes. Recientemente ha sido incorporada por la ANMAT la stevia, un nuevo edulcorante proveniente de las hojas de planta Stevia Rebaudiana.

Si bien no se demostrado la seguridad de los edulcorantes durante el embarazo, se acepta el consumo de acesulfame K, aspartame y sucralosa dentro de los límites autorizados para la ingesta diaria; en cambio, se sugiere no utilizar sacarina ni ciclamatos durante el embarazo y la lactancia.

\section{Vitaminas y minerales}

Dentro de una alimentación completa y balanceada su aporte es suficiente, no existiendo evidencias respecto a que la administración de suplementos con vitaminas, micronutrientes $y$ minerales a los pacientes con DMT2 produzca efectos beneficiosos. Tampoco ha mostrado beneficios el agregado de antioxidantes como vitaminas $E, C$ y betacarotenos $(\mathbf{A})^{26,27}$.

La ingesta de sodio en la población general debería ser menor a $2.300 \mathrm{mg} / \mathrm{dí}$, siendo esto apropiado también en personas con DMT2 (B) ${ }^{2}$.

\section{Alcohol}

Se debe desalentar su consumo, limitándolo a lo sumo a 5-10\% del VCT, sin exceder los $30 \mathrm{~g} /$ día (dos ingestas diarias). Ejemplos de una ingesta: $200 \mathrm{ml}$ de cerveza, 75-100 $\mathrm{ml}$ de vino ó $25 \mathrm{ml}$ de alcoholes destilados (cada uno de ellos equivalen a 10-15 g /día de alcohol).

\section{Adaptación a comorbilidades}

\section{Hipertensión arterial}

Se debe restringir la ingesta de sodio a menos de $2,4 \mathrm{~g}$ diarios ( $6 \mathrm{~g}$ de cloruro de sodio); no se recomienda indicar menos de 1,5 g/día, dado que trabajos publicados han demostrado incremento de mortalidad en pacientes con DM con esa indicación ${ }^{28}$. Debe asegurarse el aporte de potasio, magnesio y calcio con vegetales, frutas y lácteos.

Insuficiencia renal crónica. Fórmula sintética29,30,31

1. Carbohidratos: $50-60 \%$ del VCT.

2. Proteínas: $0,8 \mathrm{~g} / \mathrm{kg}$ teórico/día.

3. Grasas totales: $<30 \%$ del VCT.

- Grasas saturadas: $<10 \%$ del VCT.

- Colesterol: <de $200 \mathrm{mg} / \mathrm{dí}$.

4. Sodio: <de 2,3 g/día.

5. Fósforo:

- Estadio 1-2: 1,7 g/día.

- Estadio 3-4: 0,8-1,0 g/día.

6. Potasio:

- Estadio 1-2: >4 g/día.

- Estadio 3-4: 2,4 g/día.

\section{Obesidad}

Para la pérdida de peso tanto las dietas restringidas en carbohidratos como en grasas pueden ser efectivas en el largo plazo $(\mathbf{A})^{32}$.

En este caso se sugiere tener en cuenta que:

1. La cantidad mínima de HC digeribles es de $130 \mathrm{~g} / \mathrm{día}$; esta cantidad provee una adecuada cantidad de glucosa como fuente de energía para el SNC sin necesidad de sintetizar glucosa a partir de proteínas o grasas ingeridas (gluconeogénesis).

2. Si la dieta hipocalórica es restringida en $\mathrm{HC}$ y se compensa el VCT con grasas y proteínas se debe vigilar el perfil lipídico y la función renal, más aún en pacientes con nefropatía. Asimismo, hay que ajustar la terapéutica farmacológica según la necesidad de cada paciente (E).

3. Si la dieta hipocalórica es restringida en grasas y se compensa el VCT con HC, eventualmente se debe considerar el efecto desfavorable de un índice glucémico elevado y un probable incremento secundario de los triglicéridos $(\mathbf{E})$.

\section{Recomendaciones sobre el plan de alimentación en la DMT2}

1. Indicar una dieta suficiente, armónica, completa, balanceada y adaptada a las necesidades individuales, culturales y económicas del paciente teniendo en cuenta su motivación e impacto sobre la calidad de vida.

2. Recomendar alimentos con bajo índice glucémico y escasa carga glucémica, con alto contenido de fibras solubles e insolubles, como frutas, vegetales, granos enteros y legumbres, con el ob- 
jetivo de mejorar el control glucémico y lipídico en adultos con DMT2 (B) $)^{33,34}$.

3. Distribuir los alimentos con carbohidratos a lo largo del día y evitar la inclusión de una cantidad excesiva de éstos en cualquiera de las comidas (A).

4. Proponer un descenso de peso racional del 5 al 10\% del inicial en los primeros seis meses de tratamiento, dado que según la OMS se demostró, de mantenerse a los 5 años, una reducción de la morbimortalidad. Un descenso de peso, aunque sea menor al $5 \%$, también puede ser beneficioso, aunque uno superior al 10\% tendrá un impacto metabólico más eficaz en el largo plazo (A).

5. Evitar o reducir el riesgo de hipoglucemia en pacientes tratados con secretagogos o insulina, y realizar los ajustes necesarios entre el plan alimentario y los medicamentos.

6. Incentivar la adhesión al plan alimentario a través de la educación nutricional, con el propósito de producir cambios en el comportamiento que motiven y ayuden a las personas a adquirir habilidades, brindando el apoyo necesario para mantener los patrones diarios de alimentación y la preparación de alimentos (B).

7. Reforzar la importancia del cuidado alimentario y la pérdida de peso en cada consulta; los cambios de hábitos no se logran sólo por enunciarlos, requiriendo apoyo y fortalecimiento permanentes $(\mathbf{E})$.

8. Desaconsejar el consumo de alimentos comercializados con la denominación "para personas con diabetes, dietéticos o light"; en caso que el paciente desee utilizar alguno de ellos se deberá leer la "información nutricional" en conjunto con él para su mejor orientación (E).

\section{Prescripción, elaboración y provisión del plan de alimentación}

1. El médico de cualquier nivel de atención debe prescribir un plan alimentario adecuado, individualizado y adaptado al momento biológico (E), particularmente en pacientes de reciente diagnóstico, sin complicaciones o con comorbilidades leves o ausentes.

2. Un profesional con experiencia o competencia en nutrición establecerá el plan de alimentación en casos complejos, con comorbilidades severas como obesidad, hipertensión, dislipidemia, etc., o presencia de complicaciones como insuficiencia renal, insuficiencia cardíaca, etc., o situaciones especiales como el embarazo, etc., o ante toda circunstancia en la que el Clínico considere necesaria, siempre que ésta sea posible, una derivación oportuna.
3. Un Nutricionista Dietista o Lic. en Nutrición, entrenado en el manejo del paciente con DM, tomará a cargo la elaboración del plan de alimentación (B) ${ }^{35}$ y colaborará con la educación y el asesoramiento nutricional.

4. Toda persona con DM que no logre los objetivos nutricionales y cambios en el comportamiento deberá ser referida a un nivel de atención donde se le pueda brindar tratamiento especializado ${ }^{35}$.

\section{- Actividad física y/o ejercicio}

Diversos estudios epidemiológicos indican que las personas que mantienen una forma de vida activa tienen menos probabilidades de desarrollar alteraciones en la tolerancia a la glucosa y DMT2. Más aún, se encontró que el efecto protector del ejercicio fue mayor en aquellos individuos con más susceptibilidad y riesgo de desarrollar la patología ${ }^{36}$.

Se demostró que la realización de ejercicios regulares incluso en personas adultas mayores reduce la resistencia a la insulina y la DMT2, respecto de sujetos sedentarios de la misma edad; asimismo mantener una actividad física regular es el mejor predictor del mantenimiento de la pérdida de peso 37,38,39.

El ejercicio integrado a planes de cambios en el estilo de vida ha sido eficaz para evitar o retardar el inicio de DM en personas con tolerancia a la glucosa alterada (TGA) $)^{40,41,42,43}$.

Las evidencias demuestran un descenso de A1c de $0,6 \%$ a $0,66 \%$ (análisis sistemático de Boule et al. ${ }^{44}$, de Thomas et al. ${ }^{45}$, aunque para Kelley no fue significativo) ${ }^{46,47}$. Existen además cambios favorables en el perfil lipídico por el ejercicio en la DMT2, con descenso de triglicéridos, ascenso del c-HDL y disminución significativa del c-LDL. A diferencia de lo que ocurre en la población general, en las personas con DM no se han encontrado resultados consistentes respecto de la mejoría de la presión arterial| ${ }^{48}$.

Si bien en el estudio Look AHEAD hubo un descenso de peso en el primer año de $8,6 \%$ vs $0,7 \%$ en el grupo control, al final del estudio la relación fue de $6 \%$ vs 3,5\%. La intervención con cambios en el estilo de vida sobre la pérdida de peso y de $\mathrm{HbA} 1 \mathrm{c}$ no redujo riesgo cardiovascular en pacientes con DMT2 con sobrepeso u obesidad'.

Ha sido demostrado que aún en individuos sedentarios un leve incremento en la actividad física mejora el riesgo cardiovascular $(\mathrm{RCV})^{49}$.

En la indicación del ejercicio tienen importancia el tipo, el tiempo de realización, la intensidad 
y la gradualidad con la que ésta se adecua a cada individuo y luego se acrecenta en la medida que la condición del diabético lo permite.

\section{Cuidados particulares en una persona con DMT2}

Las personas con DMT2 a menudo tienen dificultades para hacer ejercicios físicos debido a obesidad, artropatías, etc., presentando mayores riesgos de lesiones o la posibilidad de exacerbar enfermedades subyacentes o complicaciones de la DM, por lo que es prudente efectuar una evaluación previa al comienzo de la actividad.

Se deberá realizar:

1. ECG de reposo: (D).

- A mayores de 40 años.

- A los pacientes con más de 15 años de enfermedad.

- A los que practiquen deportes de competición.

- A quienes presenten HTA, proteinuria, reducción de pulsos o soplos vasculares independientemente de la edad.

2. ECG de esfuerzo (prueba ergométrica graduada):

- Antes de iniciar una actividad física con mayor intensidad que una rápida caminata, el paciente con DMT2 sin manifestaciones de afectación cardiovascular y ECG en reposo normal debe ser estratificado en su riesgo cardiovascular a 10 años; si es $>10 \%$ se realizará una ergometría (E) (ADA).

- En pacientes con DM asintomático con ECG anormal inespecífico (D) (CDA).

- En pacientes con DM con síntomas típicos o atípicos como disnea, molestias toracoabdominales, etc.

\section{Prescripción del ejercicio}

En cuanto a la prescripción del ejercicio físico, para su correcta implementación debemos respetar las siguientes consignas:

1. El médico de cualquier nivel de atención es quien debe indicar por escrito el plan de actividad física.

2. Éste debe incluir 150 minutos semanales de ejercicios de intensidad moderada a intensa en forma gradual y progresiva, de tipo aeróbica (50 al $70 \%$ de la frecuencia cardíaca máxima) (A).

3. En ausencia de contraindicaciones, por ejemplo, hipertensión arterial, retinopatía proliferativa activa, etc., se pueden indicar ejercicios de resistencia en grupos musculares mayores como brazos, hombros y piernas, al menos dos veces por semana (A).

4. En la medida de lo posible se incorporará al profesor de educación física con un rol similar al del Lic. en Nutrición respecto del plan alimentario.

\section{Ejercicios en presencia de complicaciones de la DM y según su medicación}

1. Retinopatía: los ejercicios vigorosos aeróbicos y los de resistencia están contraindicados en presencia de retinopatía proliferativa y no proliferativa severa.

2. Neuropatía periférica: los ejercicios de impacto no deben realizarse en pacientes con hipoestesia marcada o con pie de Charcot. En estos casos se sugiere natación, bicicleta o ejercicios de miembros superiores, etc.

3. Neuropatía autonómica cardíaca: se manifiesta por hipotensión postural, taquicardia persistente sin adaptación al esfuerzo y está asociada con alto riesgo de eventos cardiovasculares. Estos pacientes deben ser profundamente evaluados antes de iniciar cualquier plan de actividad física, cuya intensidad deberá ser a lo sumo de leve a moderada.

4. Albuminuria y nefropatía: la actividad física puede aumentar transitoriamente la proteinuria pero no hay evidencia respecto de que acelere su progresión, por lo que no existen restricciones.

5. Insulinas, drogas que aumentan su secreción y análogos de la insulina: los pacientes medicados con insulina, análogos, sulfonilureas (SUs) y meglitinidas podrían desarrollar hipoglucemias durante y luego de finalizado el ejercicio. Si se detecta una glucemia menor a $100 \mathrm{mg} / \mathrm{dl}$ previa al ejercicio, el paciente debe ingerir $20 \mathrm{~g}$ de hidratos de carbono simples.

\section{Adherencia}

No obstante las evidencias de los beneficios del ejercicio en personas con DMT2, el médico no suele prescribirlo con la frecuencia necesaria y tiene pobre adherencia por parte del paciente.

\section{Como prescribir actividad física}

Para mejorar el control de su glucemia, disminuir o mantener el peso corporal y/o reducir el riesgo de enfermedades cardiovasculares se recomienda un plan de al menos 150 minutos semanales, desarrollados en 3 a 5 sesiones semanales, de actividad aeróbica al 50-70\% de su frecuencia cardíaca máxima (en sedentarios se puede usar la fórmula FC máx. = 220 - edad), junto con ejercicios de resistencia que incluyan grandes grupos 
musculares de miembros inferiores, superiores y tronco, en 3 series de 6-10 repeticiones, con cargas leves a moderadas.

\section{DROGAS PARA ELTRATAMIENTO DE LA DMT2 - Generalidades}

Para prescribir alguna de las drogas descriptas a continuación se deberá considerar:

1) Evaluar las características fisiopatológicas y clínicas de cada paciente en particular y el estadio evolutivo de su enfermedad (A).

2) Si hubiera necesidad de combinar dos o más drogas para alcanzar las metas de control metabólico, asociar fármacos con mecanismos de acción complementarios (A).

3) El efecto reductor sobre la glucemia expresado por el porcentaje de disminución de la $\mathrm{HbA} 1 \mathrm{c}$, teniendo en cuenta que independientemente del mecanismo de acción de cada droga la eficacia del fármaco aumenta en función de su valor inicial: cuanto más alto sea, mayor será la reducción observada $(\mathbf{A})$.

4) El tiempo necesario para determinar la eficacia de cada droga, dado que éste varía según cuál se elija y su forma farmacéutica (A).

5) Que las metas terapéuticas generalmente se logran con dosis sub-máximas de la mayoría de las drogas (B).

6) Que salvo algunas SUs y la metformina, las drogas utilizadas para el tratamiento de la DMT2 tienen un costo elevado y pueden no tener cobertura total por parte de las entidades de financiamiento de la salud. Ante la falta de evidencia de la relación costo-efectividad de algunas de las drogas analizadas, en el momento de la prescripción uno de los criterios a considerar será la accesibilidad al medicamento (E).

\section{Drogas que reducen la insulinorresistencia (insulino-sensibilizadoras) \\ - Metformina}

- Modo de acción y efecto sobre mecanismos patogénicos. Es un potente agente insulinosensibilizador que actúa primariamente disminuyendo la producción hepática de glucosa y adicionalmente mejorando la sensibilidad periférica a la insulina, disminuyendo un 35-40\% la gluconeogénesis hepática y también la glucogenólisis; este efecto se traduce sobre todo en la reducción de la concentración de la glucosa plasmática de ayunas. A nivel molecular activa la AMP-Kinasa, enzima presente en el hepatocito, la célula muscular esquelética, el adipocito, la célula $\beta$ pancreática y el cardiomiocito ${ }^{50}$.

Mejora además en un 18-22\% la utilización periférica de glucosa aumentando:

1. La captación periférica de glucosa a nivel del músculo esquelético como consecuencia de la translocación del GLUT-4 desde el citosol a la membrana plasmática y de la mejoría en la fosforilación del complejo IRS del receptor de insulina.

2. El metabolismo no oxidativo de la glucosa a través de la síntesis de glucógeno.

3. El metabolismo oxidativo de la glucosa a través de la glucólisis.

4. La expresión del gen de GLP-1.

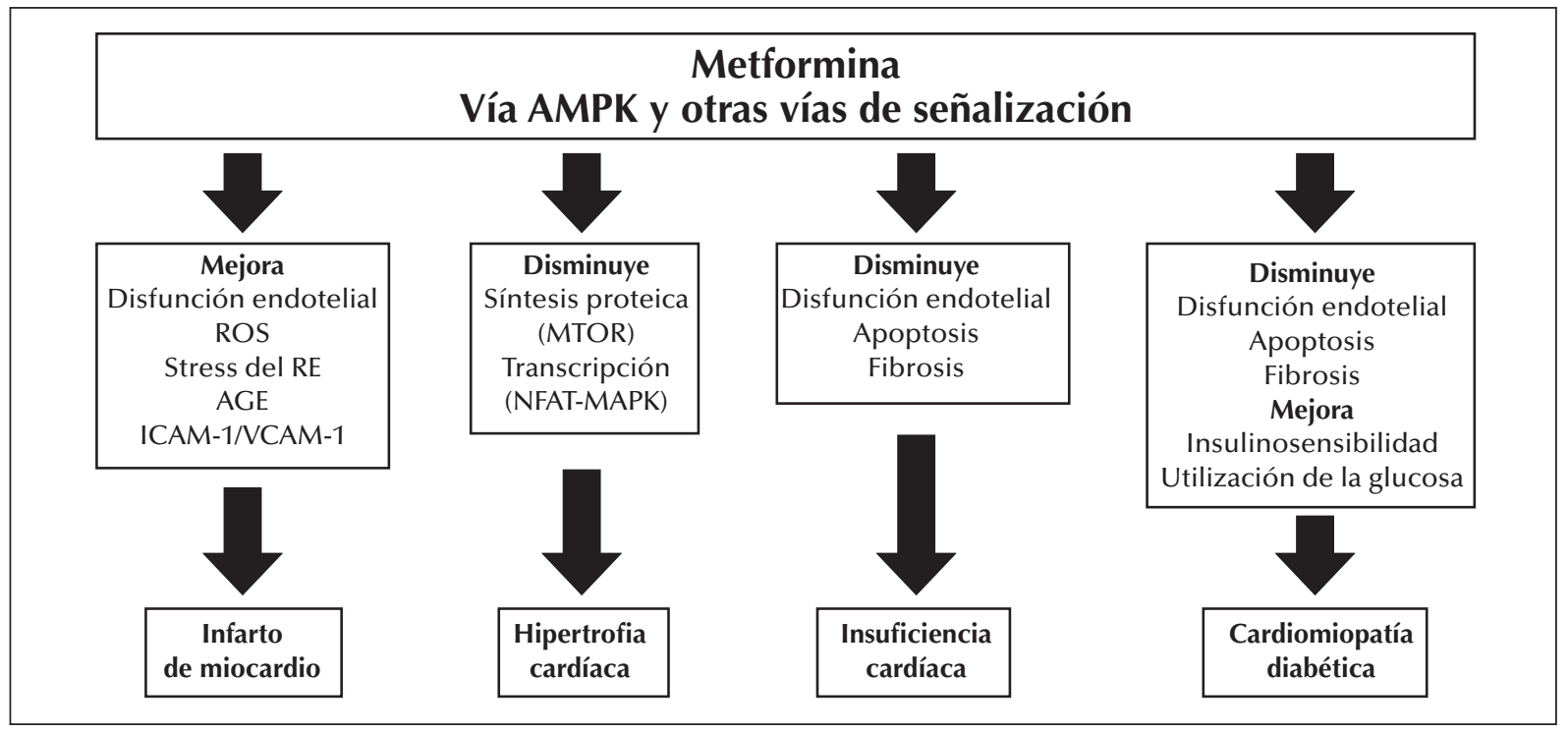

Gráfico 1: Metformina: desde los mecanismos de acción a la terapia ${ }^{51}$. Efectos de la metformina: principales mecanismos cardioprotectores (modificado de: Main putative molecular mechanisms involved in the cardioprotective effects of metformin. Foretz M, et al. Metformin: from mechanisms of action to therapies. Cell Metab 2014; 20 (6): 957). 
- Eficacia. Reduce la HbA1c entre un 1,5-2\% dependiendo de su valor inicial, disminuye los niveles circulantes de insulina, por su mecanismo de acción no genera hipoglucemia, ni aumento de peso y reduce los niveles circulantes de ácidos grasos libres y triglicéridos.

- Efectos sobre la masa y función de las céIulas $\beta$. Disminuye la lipo y glucotoxicidad sobre el islote pancreático y mejora secundariamente la función de las células $\beta$ pancreáticas.

- Dosis. Se recomienda comenzar con una dosis baja de 500 a 850 mg, 1 ó 2 veces por día con las comidas principales; después de 5 a 7 días, si no hay efectos indeseables gastrointestinales, se aumenta a 850 ó 1.000 mg 2 veces al día; de aparecer intolerancia, se regresa a la dosis anterior y se intenta aumentar nuevamente a posteriori o se cambia a la forma XR, de liberación prolongada, que se ofrece en concentraciones de 500, 750 y 1.000 mg. La dosis máxima efectiva aprobada en nuestro país es de 2.000 mg existiendo sólo un aumento ligero de eficacia con dosis de $2.500 \mathrm{mg}$ diarios ${ }^{52}$.

- Seguridad y efectos adversos. Los efectos adversos más frecuentes son gastrointestinales y consisten en náuseas, diarrea, anorexia, molestia abdominal y sabor metálico, y ocurren en el 10\% de los casos. En una cuarta parte de ellos, obligan a suspender el tratamiento y no son dependientes de la dosis por encima de 1.000 mg/día ${ }^{46}$.

Su uso está contraindicado en las siguientes circunstancias $46,53,54,55,56$ :

1. Compromiso renal, con creatinina plasmática $>1,5 \mathrm{mg} / \mathrm{dl}$ en hombres o $>1,4 \mathrm{mg} / \mathrm{dl}$ en mujeres o filtrado glomerular $<$ de $30 \mathrm{ml} /$ minuto.

2. En toda situación que lleve a la hipoxia tisular, como en la insuficiencia cardíaca descompensada, insuficiencia respiratoria, sepsis, etc.

3. Insuficiencia hepática, incluyendo la hepatopatía alcohólica; si bien la metformina no tiene metabolización hepática puede aumentar la concentración plasmática de ácido láctico.

4. En el abuso de alcohol porque puede provocar toxicidad hepática aguda ${ }^{57}$.

\section{- Debe usarse con precaución en:}

1. Pacientes con filtrado glomerular <de 45 $\mathrm{ml} /$ minuto.

2. Mayores de 80 años.

3. Administración intravenosa de agentes de contraste radiográficos: en este caso se debe suspender 48 hs antes y reiniciar 48 hs después.

4. Cirugías programadas de mediana $\mathrm{o}$ alta complejidad: se debe suspender 48 hs antes y reiniciar 48 hs después.

Cabe consignar que la acidosis láctica es una complicación extremadamente rara, menos de 1 caso por cada 100.000 pacientes tratados pero potencialmente fatal.

- Factores de riesgo cardiovascular y cambios significativos a largo plazo. La mayoría de los efectos sobre el aparato cardiovascular se debe a propiedades intrínsecas de la metformina, no depende de la dosis y en gran parte no son secundarios a su efecto antihiperglucemiante.

Se reconoce:

1. La mejoría:

a) Del perfil lipídico con descenso de la concentración de triglicéridos, de ácidos grasos libres, de cLDL, c-VLDL, colesterol total y elevación del c-HDL.

b) De la fibrinólisis y la disminución de la hipercoagulabilidad por descenso del PAI-1 (activador tisular de plasminógeno) y de la agregación y adhesión plaquetaria.

c) De la función diastólica.

d) De la función endotelial.

e) De marcadores de inflamación.

2. La disminución (modesta) de la presión arterial.

La metformina reduce los eventos macrovasculares en pacientes con DMT2. En el UKPDS bajó un $36 \%$ la mortalidad y un 39\% el infarto de miocardio en personas con DMT2 y sobrepeso ${ }^{58,59,60,61}$.

\section{- Recomendaciones}

1. Se debería iniciar con metformina en conjunto con cambios de estilo de vida particularmente en casos en que se comprueba una prolongada evolución o un compromiso moderado del estado metabólico y/o clínico (A).

2. Comenzar con metformina de no alcanzar las metas de control glucémico con el plan de alimentación, el ejercicio y la pérdida de peso, particularmente en casos de leve compromiso clínico y/o metabólico.

3. Se puede utilizar como monodroga o en combinación con SUs, iDPP-4, aGLP-1, meglitinidas, TZD, inhibidores de alfa glucosidasa, iSGLT-2, insulina y sus análogos (B).

\section{-Tiazolidindionas (TZD o glitazonas) - Modo de acción y efecto sobre mecanismos patogénicos. Las TZD disponibles en Argentina son pioglitazona y rosiglitazona; ejercen su acción como agonistas de los receptores nucleares PPAR $\gamma$, responsables de la regulación de la transcrip- ción génica. Estos receptores PPAR $\gamma$ se encuen-}


tran predominantemente en los adipocitos, por lo cual regulan la adipogénesis y secundariamente el metabolismo de lípidos y de glucosa generando una disminución en la concentración de ácidos grasos libres y glucosa circulantes. Por su modo de acción, mejoran la sensibilidad periférica a la insulina y en menor escala reducen la producción hepática de glucosa.

Existen también receptores PPAR $\gamma$ en el endotelio vascular, macrófagos, células espumosas (donde ejercen actividad antiinflamatoria), células $\beta$ pancreáticas, mama, colon y próstata.

- Eficacia. Cuando se emplean en monoterapia las TZD reducen la $\mathrm{HbA} 1 \mathrm{c}$ de un 0,5 a un $1,5 \%{ }^{62}$, disminuyen los niveles circulantes de insulina, ácidos grasos libres, marcadores de inflamación vascular (como la PCR y la interleukina 6) y aumentan los niveles circulantes de adiponectina ${ }^{63}$.

En el ADOPT, un estudio aleatorizado controlado, la rosiglitazona demostró que administrada a pacientes con DM de reciente diagnóstico, mantuvo el control glucémico por mayor tiempo que las SUs y la metformina (57 vs 33 vs 45 meses respectivamente) $)^{64}$.

- Efectos sobre la masa de las células $\beta$. Datos provenientes de experiencias en animales sugieren una protección potencial del islote cuando se las compara con los secretagogos del grupo de las SUs, pero no se ha demostrado este efecto en seres humanos.

\section{- Dosis}

1. Pioglitazona: 15 , 30 ó 45 mg, una vez al día, siendo la dosis máxima $45 \mathrm{mg} / \mathrm{día}$, no requiriendo ajustes en caso de insuficiencia renal o en ancianos.

2. Rosiglitazona: la dosis inicial es de $4 \mathrm{mg}$ una vez al día pudiéndose incrementar al cabo de 12 semanas a la dosis máxima de $8 \mathrm{mg}$.

- Seguridad y tolerabilidad. Tanto la pioglitazona como la rosiglitazona aumentan el riesgo de insuficiencia cardíaca $(R R=2)$, siendo la evidencia más controvertida respecto de otros eventos cardiovasculares.

En el PROACTIVE, un estudio realizado con pioglitazona en prevención primaria y secundaria, se demostró una disminución significativa del riesgo de un índice combinado que incluía muerte, accidente cerebrovascular (ACV) e infarto de miocardio (IAM) ${ }^{65}$.

En un estudio de metaanálisis que incluyó 42 estudios randomizados controlados, se encontró asociación entre la rosiglitazona y un aumento significativo en el riesgo de IAM $^{66}$. A posteriori, en el estudio RECORD, se demostró que en pacien- tes tratados con rosiglitazona más metformina o más SUs vs metformina más SUs, no hubo una diferencia significativa respecto de internación o muertes por eventos cardiovasculares; si bien los datos sobre IAM no fueron concluyentes y persistió la mayor incidencia de insuficiencia cardíaca, se estimó que la rosiglitazona no aumentó el riesgo de morbimortalidad cardiovascular total comparada con agentes hipoglucemiantes estándar ${ }^{67}$.

\section{- Otros efectos adversos}

1. Aumento de peso por diferenciación de adipocitos y aumento de su masa.

2. Edema leve o moderado.

3. Anemia.

4. Incremento del riesgo de fracturas, sobre todo en las extremidades, con mayor frecuencia en el género femenino, siendo de 0,8 casos/año por cada 100 mujeres en tratamiento con pioglitazona, similar al observado con rosiglitazona en los estudios ADOPT y RECORD.

5. Edema de mácula y cataratas.

\section{- Contraindicaciones}

1. Insuficiencia cardíaca grados III y IV.

2. Enfermedad hepática activa, con transaminasas séricas $>2,5$ veces el límite superior normal.

3. Edema severo.

4. En mujeres postmenopáusicas con osteoporosis y/o antecedentes de fracturas.

5. Embarazo y lactancia.

6. Población pediátrica.

7. No se requiere ajuste de dosis en caso de insuficiencia renal o ancianos.

La posición de la ANMAT para rosiglitazona -según la Resolución № 706/93, de agosto de 2007, fundamentada en los estudios ADOPT, DREAM y el análisis preliminar del RECORD- es mantener su indicación para pacientes con DMT2, advirtiendo respecto del riesgo de ser usada en pacientes con enfermedad cardiovascular64,67,68,69. La SAD en su momento transcribió las disposiciones de la EMA y la FDA; la primera sostenía que los beneficios asociados al uso de rosiglitazona no eran mayores que los riesgos, recomendando la suspensión gradual de la autorización a su comercialización en Europa, y sugirió que los pacientes no interrumpieran su terapéutica pero que evaluaran con su médico tratamientos alternativos adecuados y que los profesionales no siguieran recetando rosiglitazona; la segunda recomendó su uso sólo cuando no se pueda utilizar otro agente oral (disponible en: www.sad.org.ar).

Posteriormente, el 25 de noviembre de 2013, 
la FDA evaluó que las medicaciones con rosiglitazona no incrementan el riesgo de IAM comparadas con SUs y metformina, revocando la restricción impuesta en 2010.

En nuestro país la ANMAT adoptó las siguientes medidas:

1. Reformulación de determinados ítems contenidos en el texto del prospecto, que implicaron limitaciones en su utilización.

2. Modificación de su condición de venta, en adelante por receta archivada.

3. Instrumentación de un plan de farmacovigilancia o plan de minimización de riesgos.

4. No dar curso a ensayos clínicos que involucren a esta droga.

Respecto de la asociación de pioglitazona con cáncer de vejiga, finalmente no se demostró en un estudio realizado con un seguimiento a 10 años $^{70}$.

- Factores de riesgo cardiovascular y cambios significativos a largo plazo. La pioglitazona tiene un efecto beneficioso sobre el perfil lipídico, aumenta el c-HDL y disminuye los TG produciéndose por la activación del receptor hepático PPAR $\alpha$.

Las TZDs disminuyen el estado inflamatorio vascular y reducen levemente la presión arterial sistólica en el orden de los 2 a $3 \mathrm{mmHg}$.

Ambas drogas tendrían efectos favorables en pacientes con esteatosis hepática ${ }^{71}$.

\section{- Recomendaciones}

1. Cuando las metas de tratamiento no se alcanzan con cambios de estilo de vida asociadas a todos los ADs o a insulina (A).

2. En monoterapia en casos de intolerancia a metformina (A).

\section{Drogas que estimulan o potencian la secreción de insulina. \\ Fármacos que estimulan directamente la secreción de insulina o secretagogos}

\section{- Sulfonilureas (SUs)}

- Mecanismo de acción. Aumentan la secreción de insulina uniéndose a receptores específicos asociados al canal de $K_{\text {ATP }}$ dependiente ubicados en la membrana de la célula $\beta$, denominados SUR (receptores de SUs); su efecto es independiente de la concentración/metabolización de la glucosa, siendo su secuencia la siguiente: cierre de los canales de $\mathrm{K}_{\text {ATP }} \rightarrow$ apertura de los canales de $\mathrm{Ca}^{2}+$ voltaje-dependientes $\rightarrow$ aumento del calcio citosólico $\rightarrow$ secreción de insulina.
Existen dos tipos de estos receptores: SUR1 pancreáticos y SUR-2 extra pancreáticos; teóricamente las SUs tendrían mayor afinidad por los SUR-1, por lo que en la práctica clínica no habría interferencia con el preacondicionamiento isquémico cardíaco.

Las SUs no modifican la sensibilidad de los tejidos a la insulina ni a nivel experimental ni clínico; para cada una de estas familia de drogas se deberá considerar su vida media y la modalidad de administración.

- Eficacia. El descenso de la HbA1c inducido por diferentes drogas depende de su nivel inicial, por lo que el correspondiente a las SUs presenta un amplio rango que oscila entre el 0,9 y el 2,5\%, con una media de 1,5,\%69,72. Empleadas en monoterapia, la disminución de la glucemia es relativamente rápida en comparación con otros fármacos; su eficacia tiende a reducirse con el tiempo de tratamiento64,73.

- Efectos sobre la masa y función de las céIulas $\beta$. No hay evidencia respecto de que las SUs aceleren el deterioro progresivo de la masa y función de las células $\beta^{67}$; en algunos ensayos clínicos se ha observado que algunas SUs incrementan el cociente proinsulina/insulina, un marcador del grado de exigencia funcional ("estrés") de las células $\beta^{74}$, pero no se ha demostrado que esto implique progresión de su deterioro.

- Dosis recomendadas. Las SUs disponibles en nuestro medio son la glibenclamida, gliclazida, glimepirida, glipizida y clorpropamida. Aunque el rango terapéutico de la mayoría de ellas es amplio, las dosis clínicamente efectivas suelen ser menores que las dosis máximas.

1. Clorpropamida: hasta $500 \mathrm{mg}$.

2. Glibenclamida: hasta $15 \mathrm{mg}$.

3. Gliclazida: en su formulación habitual, dosis máxima de 320 mg y en la de liberación modificada (MR) hasta $120 \mathrm{mg}$ (4 comprimidos de $30 \mathrm{mg}$ ó 2 de $60 \mathrm{mg}$ ).

4. Glimepirida: dosis máxima $8 \mathrm{mg}$.

5. Glipizida: hasta $15 \mathrm{mg} / \mathrm{día}$.

Las únicas SUs que se administran en una sola toma diaria son la clorpropamida y la gliclazida de liberación modificada, las demás deben ingerirse antes de las comidas principales.

- Seguridad y efectos adversos. Dado que las SUs estimulan la secreción de insulina independientemente de los valores de glucemia, su administración aumenta el riesgo de hipoglucemias ${ }^{75}$.

Su vida media no es uniforme, siendo mayor la 
frecuencia de hipoglucemias con las de vida media prolongada, por lo que se debe evitar su empleo en personas de edad avanzada o con fallo renal o hepático. La clorpropamida es la de mayor vida media, se elimina por vía renal y consecuentemente debe evitarse su uso en ancianos y en personas con descenso del clearence de creatinina; por el contrario, un reciente metaanálisis concluyó que la gliclazida es la SU que se asoció con menor riesgo de hipoglucemias severas ${ }^{76}$. Otro efecto no deseado de las SUs es el aumento de peso en promedio de $2 \mathrm{~kg}^{1}$.

- Factores de riesgo cardiovascular y cambios significativos a largo plazo. No existe evidencia respecto de que las SUs modifiquen el perfil lipídico o la presión arterial; diversos ensayos clínicos prospectivos multicéntricos aleatorizados no han confirmado el resultado de un estudio observacional retrospectivo que describió aumento del riesgo cardiovascular asociado al uso de $\mathrm{SUs}^{77}$.

- Etapa evolutiva de la enfermedad en la que están indicados. Se prescriben como monoterapia o asociados a ADs de mecanismo de acción complementarios cuando las metas de tratamiento no se alcanzan mediante cambios en el estilo de vida, cuidando la aparición de hipoglucemias (AACE 2015) (ADA 2015). Como grupo, las SUs tienen alta eficacia para descender la HbA1c, moderado riesgo de hipoglucemias, inducen ganancia de peso y son de bajo costo (ADA 2015).

\section{Secretores de insulina no sulfonilureicos}

\section{- Meglitinidas}

- Mecanismo de acción. Las meglitinidas o sus análogos aumentan la secreción de insulina por un mecanismo similar al de las SUs, por lo tanto su asociación no tendría fundamento farmacológico.

Su vida media es más corta que la de las SUs, por lo que deben administrarse a intervalos menores y próximas a las comidas principales ${ }^{78}$; si se omite una comida, se debe evitar ingerir la dosis correspondiente. Por otra parte, no está demostrado que modifiquen la insulinorresistencia.

- Eficacia. Disminuyen los valores de $\mathrm{HbA} 1 \mathrm{c}$ de un 0,5 a un $1,5 \%$, siendo en monoterapia menos eficaz la nateglinida ${ }^{79}$.

- Efectos sobre la masa y función de las céIulas $\beta$. No hay evidencia respecto de que modifiquen el deterioro progresivo de la masa y función de las células $\beta$.

- Dosis recomendadas. Para la repaglinida es entre 0,5 y $4 \mathrm{mg}$ antes de cada una de las comidas principales, con un máximo de $12 \mathrm{mg} / \mathrm{día}$; para la nateglinida es de hasta $120 \mathrm{mg}$ antes de cada comida, con un máximo de 360 mg/día.

- Seguridad y efectos adversos. Su efecto hipoglucemiante es más breve que el de las SUs y consecuentemente presentan menor frecuencia de hipoglucemia, pero el aumento de peso es similar ${ }^{11}$. En pacientes con fallo renal es preferible utilizar repaglinida.

- Factores de riesgo cardiovascular y cambios significativos a largo plazo. No existe evidencia respecto de que las meglitinidas modifiquen el perfil lipídico o la presión arterial.

- Etapa evolutiva de la enfermedad en la que están indicados. Como monoterapia o asociadas a ADs de mecanismo de acción complementarios, cuando no se alcanzan las metas de tratamiento empleando cambios de estilo de vida (A). Por el inicio rápido de su acción y su vida media corta, su utilización es adecuada principalmente para modificar la glucemia prandial $(\mathbf{A})$; dicho perfil de acción las hace aptas para indicarlas en vez de las SUs en personas con hábitos de alimentación irregulares o en presencia de hipoglucemias postprandiales tardías (ADA 2015).

\section{Drogas que disminuyen la absorción de la glucosa}

\section{- Inhibidores de la $\alpha$-glucosidasa}

- Mecanismo de acción. El único fármaco disponible de este grupo en nuestro medio es acarbosa; disminuye la absorción de glucosa inhibiendo la actividad de la enzima $\alpha$-glucosidasa intestinal y retardando por este medio la digestión de los polisacáridos por lo que modifica en especial a la glucemia prandial. No existe evidencia respecto de que actúe directamente sobre la secreción de insulina o la insulinorresistencia.

- Eficacia. Disminuye los valores de HbA1c de un 0,5 a un $0,8 \% 80$.

- Efectos sobre la masa y función de las células $\beta$. No existe evidencia respecto de que modifique el deterioro progresivo de la masa y función de las células $\beta$.

- Dosis recomendada. De 50 a 100 mg hasta 3 veces por día, antes de las comidas.

- Seguridad y efectos adversos. Su administración se acompaña de intolerancia gastrointestinal, meteorismo y diarrea, ${ }^{72,81}$ por lo que se 
recomienda iniciar la terapia con $50 \mathrm{mg}$ antes de las comidas principales y aumentar luego progresivamente según necesidad y tolerancia hasta alcanzar la dosis máxima de 100 mg 3 veces por día. Tiene bajo riesgo de hipoglucemia, pero suele ser mal tolerada por sus efectos gastrointestinales.

- Factores de riesgo cardiovascular y cambios significativos a largo plazo. No modifica el perfil lipídico, la presión arterial ni el peso corporal. En el estudio STOP-NIDDM se demostró disminución de la progresión a DMT2 en personas con riesgo aumentado de desarrollarla ${ }^{82}$.

- Etapa evolutiva de la enfermedad en la que están indicados. Se indica como monoterapia o asociados a ADs de mecanismo de acción complementarios cuando las metas de tratamiento no son alcanzadas con cambios de estilo de vida, situación que puede ocurrir temprana o tardíamente en la evolución de la enfermedad.

- Propiedades terapéuticas. Posee moderada eficacia para disminuir la HbA1c, no produce hipoglucemia empleada como monoterapia y tiene beneficio potencial respecto de la progresión a DMT2.

\section{Incretinas}

\section{- Agonistas del receptor de glucagón-like peptide 1 (aGLP-1)}

- Mecanismos de acción. Son sustancias que estimulan los receptores del GLP-1, restablecen su acción reducida en personas con DMT2, aumentando sus niveles circulantes por administración exógena. A diferencia de los inhibidores DPP4 (iDPP-4), logran concentraciones circulantes de un nivel farmacológico. De las moléculas existentes, la exenatida, por sus diferencias estructurales, es considerada un agonista del receptor de GLP-1 ${ }^{83}$, mientras que otras como la liraglutida y lixisenatida, por su similitud con la molécula endógena, son definidas como análogos de la GLP-1. Potencian la secreción de insulina inducida por la glucosa, efecto dependiente de la concentración de esta última en sangre, por lo cual el riesgo de hipoglucemia es bajo.

Además disminuyen la secreción de glucagón, retardan el vaciamiento gástrico e inhiben el apetito a nivel central, por lo que en conjunto favorecen el control metabólico y el descenso de peso.

- Eficacia. Al igual que otras drogas, su efecto sobre la HbA1c depende de su valor inicial, estimándose una disminución de entre el 0,5 y $1 \%$.
Con respecto al descenso de peso, los estudios muestran una reducción de entre 2 a $3 \mathrm{~kg}^{84}$.

- Efectos sobre la masa y función de las células $\beta$. En un estudio no controlado utilizando un aGLP-1 más metformina vs placebo más metformina, se mantuvo el control eficaz de la $\mathrm{HbA} 1 \mathrm{c}$ durante 3 años, utilizándola como indicador del mantenimiento de la función de las células $\beta$; dicho efecto desapareció al suspenderse la administración de la droga. En modelos animales o cultivos de islotes humanos, los aGLP-1 disminuyen la tasa de apoptosis y consecuentemente aumentan la supervivencia de las células $\beta$, aunque este efecto no es reproducible en humanos ${ }^{85}$.

- Dosis recomendadas. Actualmente en nuestro país se comercializan dos moléculas: exenatida y liraglutida; la lixisenatida, aprobada por la ANMAT por la Disposición 3.801 del 5 de junio de 2014 (disponible en: http://www.anmat.gov.ar/boletin_anmat/Junio_2014/Dispo_3801-14.pdf) no se encuentra hasta el momento en el mercado.

Exenatida: se inicia el tratamiento con dos inyecciones diarias de $5 \mathrm{mcg}, 60 \mathrm{~m}$ antes de las comidas principales, luego de un mes se puede incrementar la dosis a $10 \mathrm{mcg}$ dos veces por día dependiendo de la respuesta clínica evaluada por la eficacia y tolerabilidad.

. Liraglutida: se administra una sola vez por día, independientemente del momento prandial; se debe comenzar con 0,6 mg para luego ir escalando la dosis hasta llegar a un máximo de 1,8 mg según su eficacia y tolerancia ${ }^{86}$.

\section{- Seguridad y efectos adversos}

Exenatida: promueve el desarrollo de anticuerpos, aunque se desconoce su trascendencia clínica; si bien se han descripto casos de pancreatitis aguda, el riesgo de padecerla sería similar al registrado con glibenclamida, metformina e iDPP- $4^{87}$.

Liraglutida: también se han observado anticuerpos que no disminuyen su efecto terapéutico ${ }^{88}$.

No se ha establecido la seguridad de estas drogas a más de tres años. Los efectos colaterales más frecuentemente descritos son náuseas, vómitos y diarrea que en general ceden o disminuyen sin discontinuar el tratamiento.

- Factores de riesgo cardiovascular y cambios significativos a largo plazo. Siguiendo las recomendaciones de la FDA del año 2008, respecto de la realización de estudios de desenlaces cardiovasculares con nuevos ADs, enfocados especialmente en la seguridad cardiovascular, la lixi- 
senatida mostró no inferioridad/no superioridad vs placebo ${ }^{89}$. La liraglutida también ha sido evaluada en un estudio a largo plazo en el mismo sentido y sus resultados serán publicados próximamente; en los desenlaces cardiovasculares vs placebo habría demostrado superioridad de acuerdo a informes preliminares del productor.

El estudio LEADER evidenció que el evento combinado primario (muerte de causa cardiovascular, infarto de miocardio no fatal y stroke no fatal) se presentó en menor proporción en el grupo tratado con liraglutida respecto del placebo $(13,0 \%$ vs 14,9\%, HR:0.87; IC 95\% 0,78-0,97) en una población con DMT2 con alto riesgo cardiovascular. Entre los objetivos secundarios, la mortalidad de causa cardiovascular fue significativamente más baja en el grupo tratado con liraglutida vs placebo $(4,7 \%$ vs 6,0\%, HR: 0.78 IC 95\% 0,66-0,93) evidenciándose reducciones no significativas de stroke no fatal e infarto de miocardio no fatal ${ }^{90}$.

Perfil lipídico: se han descrito efectos favorables sobre los niveles circulantes de colesterol total, c-HDL, c-LDL y triglicéridos.

Presión arterial: algunos estudios sugieren que son capaces de disminuir la presión arterial sistólica y diastólica, con un aumento concomitante de la frecuencia cardíaca del orden de los 3 a 4 latidos por minuto ${ }^{21}$.

- Etapa evolutiva de la enfermedad en la que están indicados. Se prescriben como monoterapia o asociados a ADs de mecanismo de acción complementarios cuando no se alcanzan las metas de tratamiento, después de haber intentado cambios de estilo de vida. Esto puede ocurrir temprana o tardíamente en la evolución de la enfermedad.

\section{- Inhibidores de la DPP-4 (iDPP-4)}

Actualmente se dispone en Argentina de cinco drogas de esta familia: sitagliptina, saxagliptina, vildagliptina, linagliptina y teneligliptina; existen otras moléculas aprobadas en diferentes países y algunas en etapa de experimentación.

- Mecanismo de acción. Incrementan la secreción de insulina estimulada por glucosa e inhiben la secreción inadecuada de glucagón. Estos efectos son consecuencia del aumento de los niveles endógenos circulantes de GLP-1 y GIP (péptido insulinotrópico dependiente de glucosa) ${ }^{91,92,93}$ ya que inhiben su degradación por bloqueo de la enzima dipeptidilpeptidasa-4 (DPP-4). En consecuencia, y a diferencia de los miméticos de incre- tinas descriptos anteriormente, no logran niveles farmacológicos de GLP-1 y GIP94.

- Eficacia. En promedio disminuyen los niveles de $\mathrm{HbA} 1 \mathrm{c}$ de un 0,5 a un $0,8 \%$; tienen efecto neutro sobre el peso corporal, su eficacia metabólica y su seguridad se basan en estudios de más de 5 años de seguimiento y en el extendido uso clínico, desde su introducción en el año 200795,96,97.

- Efectos sobre la masa y función de las células $\beta$. En base a estudios en modelos animales se ha demostrado un aumento en supervivencia y masa de las células $\beta$, aunque este efecto no ha sido reproducido en seres humanos. Existen datos indirectos en cuanto a la mejoría de la función $\beta$ comparados con metformina y SUs, ya que no es necesario agregar nuevas drogas para mantener el objetivo glucémico mientras se mantiene su administración ${ }^{98}$.

\section{- Dosis recomendadas}

1. Sitagliptina: $100 \mathrm{mg}$ una vez por día.

2. Saxagliptina: $5 \mathrm{mg}$ una vez por día.

3. Vildagliptina: $50 \mathrm{mg}$ dos veces por día.

4. Linagliptina: $5 \mathrm{mg}$ una vez por día.

5. Teneligliptina: $20 \mathrm{mg}$ una vez por día, con una dosis máxima de 40 mg/día.

\begin{tabular}{|c|c|c|c|c|}
\hline Agente & $\begin{array}{l}\text { Afinidad } \\
\text { DPP-4 }\end{array}$ & Dosis & Metabolismo & Eliminación \\
\hline Sitagliptina & Alta & $50-100 \mathrm{mg}$ & Ninguno & $\begin{array}{l}\text { Renal: } \\
80 \% \text { no } \\
\text { modificada }\end{array}$ \\
\hline Vildagliptina & Alta & $50-100 \mathrm{mg}$ & $\begin{array}{l}\text { Hidroxilación } \\
\text { hepatica por } \\
\text { vía diferente a } \\
\text { la citocromo } \\
\text { P } 450\end{array}$ & $\begin{array}{l}\text { Renal: } \\
22 \% \text { no } \\
\text { modificada } \\
\text { y } 55 \% \text { como } \\
\text { metabolito } \\
\text { inactivo }\end{array}$ \\
\hline Saxagliptina & Media & $2,5-5 \mathrm{mg}$ & $\begin{array}{l}\text { Hepático: } \\
3 \text { a } 4 / 5 \\
\text { vía citocromo } \\
\text { P } 450\end{array}$ & $\begin{array}{l}\text { Renal: } \\
12-29 \% \text { no } \\
\text { modificada }\end{array}$ \\
\hline Linagliptina & Alta & $2,5-5 \mathrm{mg}$ & Ninguno & $\begin{array}{l}\text { Biliar: no } \\
\text { modificada } \\
\text { Renal: menos } \\
\text { del } 6 \%\end{array}$ \\
\hline Teneligliptina & Alta & $20-40 \mathrm{mg}$ & $\begin{array}{l}\text { Hepático } \\
\text { parcial vía } \\
\text { citocromo } \\
\text { P } 450 \text { y } \\
\text { CYP3A4 }\end{array}$ & $\begin{array}{l}\text { Renal: } 34 \% \\
\text { Hepática: } \\
66 \% \text { como } \\
\text { metabolitos }\end{array}$ \\
\hline
\end{tabular}

Tabla 3: Características principales de los iDPP4 presentes en el mercado.

- Seguridad y efectos adversos. Como se mencionó anteriormente, su efecto hipoglucemiante depende de la concentración de glucosa en sangre, por lo que el riesgo de hipoglucemia es bajo.

La asociación de los iDPP-4 con el incremento del riesgo de pancreatitis no está claramen- 
te establecida, no obstante no se recomienda su uso en pacientes con antecedentes de esta patología $87,99,100$. Tampoco hay evidencias sólidas respecto de la asociación entre el uso de iDPP-4 y cáncer pancreático ${ }^{12,32,101 .}$.

- Factores de riesgo cardiovascular y cambios significativos a largo plazo. Los iDPP-4 modifican modestamente el perfil lipídico reduciendo los triglicéridos postprandiales. Disminuyen levemente la presión arterial y tienen un efecto neutro sobre el peso corporal.

En el estudio de seguridad cardiovascular SAVOR-TIMI 53 se estableció para saxagliptina vs placebo un aumento del riesgo de insuficiencia cardíaca, con un $R R=1.27$ pero sin impacto en la mortalidad cardiovascular global ${ }^{102}$.

En el estudio TECOS con sitagliptina no se observó este evento adverso, demostrando un perfil de seguridad cardiovascular no inferior y no superior al placebo ${ }^{103}$.

Los estudios de desenlaces cardiovasculares antes mencionados se ajustan a las recomendaciones de FDA de 2008; linagliptina está siendo explorada en un estudio orientado en el mismo sentido (CARMELINA, Cardiovascular and renal outcome study with linagliptin). Hasta el momento ningún otro iDPP-4 disponible en Argentina está siendo evaluado bajo tales recomendaciones.

- Etapa evolutiva de la enfermedad en la que están indicados. Se indican como monoterapia o asociados a ADs con mecanismo de acción complementario cuando las metas de tratamiento no se alcanzan empleando cambios en el estilo de vida.

Por su mecanismo de acción y bajo riesgo de hipoglucemia son de primera elección asociadas a metformina. Por su perfil de seguridad y baja tasa de efectos adversos su empleo es ideal en adultos mayores, siendo útiles en cualquier momento evolutivo de la enfermedad.

La sitagliptina ha demostrado adición de beneficios en combinación con insulina y una prolongación del período libre de insulina exógena cuando ha sido utilizada en esquema triple con metfomina y TZD $31,32,105$.

\section{- Inhibidores del co-transportador de sodio/ glucosa tipo 2 (iSGLT-2)}

- Mecanismo de acción. Los inhibidores de los transportadores SGLT-2 (iSGLT-2) representan un cambio conceptual en el tratamiento de la DMT2 por su mecanismo de acción no insulino- dependiente; éste consiste en la reducción de la reabsorción de glucosa en el túbulo proximal causando una glucosuria de aproximadamente 60-80 g/día ${ }^{106}$. Esta característica los diferencia de otras drogas utilizadas en el tratamiento de la enfermedad favoreciendo la durabilidad de su efecto ${ }^{107}$.

- Efectividad. En estudios de seguimiento de 12 a 104 semanas, administrados como monoterapia o asociados a drogas como metformina ${ }^{108}$, glimepirida, pioglitazona, iDPP-4 ${ }^{109,110}$ o insulina, logran una disminución de la $\mathrm{HbA} 1 \mathrm{c}$ de un 0,5 a un 1,0\%, así como de la glucemia de ayuno y postprandial. En consecuencia, representan una opción interesante para emplear en cualquier momento de la evolución de la DMT2 como agentes de segunda o tercera línea o aún con insulina ${ }^{111}$. También como monoterapia en circunstancias de intolerancia a la metformina ${ }^{112}$, especialmente en pacientes con hiperfiltrado glomerular.

Dado su mecanismo de acción, su efectividad depende de los niveles de glucemia y de la función renal, perdiéndose la misma durante la insuficiencia renal; por esta razón se contraindica, por ejemplo, la administración de dapagliflozina en pacientes con filtrado glomerular $\leq 60 \mathrm{ml} / \mathrm{minu}$ to/1,73 m² 113. También están contraindicados en pacientes con DMT1.

- Efectos favorables adicionales. Incluyen bajo riesgo de hipoglucemia, pérdida de peso a expensas de la masa magra ${ }^{114}$ y disminución de la presión arterial ${ }^{115}$, lo que sugiere posibles efectos beneficiosos cardiovasculares que deberán confirmarse en nuevos estudios a largo plazo ${ }^{116,117}$. Recientemente un estudio prospectivo aleatorizado con 7.020 pacientes con DMT2 y alto riesgo de eventos cardiovasculares tratados con empagliflozina más tratamiento estándar durante una mediana de 3,1 años demostró reducción de la tasa del evento primario compuesto (infarto de miocardio o ACV no fatal) y de muerte por cualquier causa comparado con el placebo ${ }^{118}$.

Los restantes iSGLT-2 disponibles en Argentina se encuentran en evaluación respecto de sus desenlaces cardiovasculares bajo diseños que siguen las guías recomendadas por la FDA en 2008.

- Efectos indeseables. La producción de glucosuria se ha asociado a cambios metabólicos tales como aumento del glucagón, de la gluconeogénesis, disminución del consumo de glucosa por los tejidos y de los niveles de insulina circulante, con aumento concomitante de la movilización de lípidos y del nivel de ácidos grasos libres, además de aparición de algunos episodios de cetoacidosis 
con glucemia no muy elevados que deberán ser evaluados para interpretar su riesgo potencial ${ }^{119}$.

Otro efecto metabólico indeseable es el aumento del colesterol total, c-LDL y c-HDL, sin cambios en la relación LDL/HDL o triglicéridos.

Pueden presentar además urgencia miccional, disuria e infecciones urinarias ${ }^{120}$, mostrando diferencias significativas vs placebo en pacientes con antecedentes de infecciones urinarias recurrentes e infecciones genitales ${ }^{121}$ como vulvo-vaginitis, balanitis, balanopostitis micóticas, etc., por lo que el antecedente debe buscarse antes de su prescripción. En la mayoría de los casos estos eventos no indujeron al abandono del fármaco por tratarse en general de episodios únicos durante las primeras semanas del tratamiento, sin recurrencia y con remisión bajo el tratamiento habitual ${ }^{122}$.

Menos común es la aparición de hipotensión postural que ha determinado su contraindicación asociada a diuréticos de asa, así como en pacientes proclives a la depleción de volumen. Se sugiere cautela para su indicación en adultos mayores ya que hay poca experiencia en pacientes con más de 75 años.

- Dosis y presentaciones. En general esta familia de drogas comparte las características farmacocinéticas de rápida absorción oral y vida media prolongada, administrándose una vez al día. En Argentina se disponen de tres fármacos de este grupo:

Dapagliflozina: su dosis es de $10 \mathrm{mg} / \mathrm{día}$, administrada en una sola toma en cualquier horario, sin relación con la ingesta, sugiriéndose a la mañana por el aumento de diuresis del orden de los $400 \mathrm{ml} /$ día que genera; no presenta interacciones medicamentosas significativas.

Empaglifozina: tanto en monoterapia como en combinación, la dosis inicial recomendada es de $10 \mathrm{mg}$ una vez al día, administrada en un sola toma diaria, pudiéndose aumentar la dosis máxima de 25 mg; no presenta interacciones medicamentosas significativas.

Canagliflozina: la prescripción inicial recomendada es de 100 mg una vez al día, pudiendo aumentarse a $300 \mathrm{mg}$ en pacientes que toleran esta dosis, tienen una TGFe $\geq 60 \mathrm{ml} / \mathrm{min} / 1,73 \mathrm{~m}^{2}$ y necesitan un control glucémico más estricto. No presenta interacciones medicamentosas significativas.

\section{- Tratamiento farmacológico de la obesidad en pacientes con DMT2}

En la obesidad es factible indicar farmacoterapia en pacientes con:
1. Índice de masa corporal $(\mathrm{IMC}) \geq 30 \mathrm{~kg} / \mathrm{m}^{2} \sin$ comorbilidades o factores de RCV.

2. $I M C \geq 27 \mathrm{~kg} / \mathrm{m}^{2}$ con comorbilidades o factores de $R C V$.

Ante el fracaso de la terapia nutricional y de los CEV, cuando no se consigue una pérdida del 5 al 10\% del peso inicial o bien cuando una vez alcanzado el objetivo no se puede mantener el peso corporal.

En nuestro país, orlistat es la única medicación aprobada por la ANMAT para indicar en este grupo de pacientes; actúa inhibiendo la lipasa pancreática, enzima que descompone los triglicéridos en el intestino; por su acción, no son hidrolizados en ácidos grasos absorbibles y se excretan por las heces sin digerirse.

Es una droga eficaz en obesos con DMT2, ya que mejora el control glucémico y metabólico produciendo cambios favorables en los niveles de lípidos; estos pacientes alcanzan un descenso de peso significativo del $5 \%$ en el $35-73 \%$ de los casos. En un $14-41 \%$ de los pacientes también se observa mejoría significativa de factores de RCV, con descenso de colesterol total, colesterol de LDL, glucemia en ayunas y tensión arterial ${ }^{123}$.

Su dosis es de $120 \mathrm{mg}$ dos o tres veces al día, recomendándose indicar antes, durante o hasta no más de una hora después de las comidas que contienen grasas. Si una comida no se ingiere o la misma no contiene grasas es conveniente omitir la dosis correspondiente ${ }^{124}$.

Debido a su mecanismo de acción puede causar considerables efectos adversos gastrointestinales como flatulencia, urgencia fecal, heces grasas, aumento de la defecación e incontinencia fecal; algunos estudios han demostrado que los mismos pueden reducirse por la coadministración de suplementos que contengan fibras ${ }^{125}$. Entre los efectos adversos menos frecuentes se encuentran descriptos: deficiencia de vitaminas liposolubles, reacciones de hipersensibilidad, nefro y hepatotoxicidad ${ }^{126}$.

\section{INSULINOTERAPIA EN LA DMT2}

\section{Insulinas humanas y análogos de la insulina \\ - Etapa evolutiva de la enfermedad en la que están indicados. La insulinoterapia se indica en las siguientes situaciones clínicas:}

1. Como tratamiento inicial en pacientes de reciente diagnóstico que presentan signos y síntomas de descompensación metabólica moderada a severa, como adelgazamiento y cetosis, enferme- 
dades intercurrentes, cirugía o glucemias superiores a $240 \mathrm{mg} / \mathrm{dl}$ en ayunas y/o HbA1c mayor a $9 \%$.

2. Como tratamiento complementario en pacientes tratados con ejercicio, dieta y diferentes fármacos que no han alcanzado las metas de tratamiento individualizado (D) ${ }^{127}$.

\section{- Indicación de insulinoterapia transitoria}

Se indica en las siguientes situaciones clínicas:

En pacientes con hiperglucemia sintomática, aún con niveles glucémicos y de HbA1c menores a los mencionados.

Personas con DMT2 que presenten descompensación glucémica severa por una situación médica y/o quirúrgica. La evolución del estado clínico o la afección intercurrente determinarán la transitoriedad o permanencia del tratamiento. Ejemplos: embarazo (A), cirugías (D), infecciones graves (D), tratamiento con fármacos hiperglucemiantes (D), traumatismo graves (D), quemaduras (D), desnutrición (A), alimentación por vías de excepción, infarto de miocardio (B), ACV (B) y en todos aquellos pacientes internados en situación crítica (A) y no crítica no mencionadas previamente.

\section{- Indicación de insulinoterapia definitiva}

Se indica en las siguientes situaciones clínicas:

1. Como tratamiento en pacientes tratados con ejercicio, dieta y diferentes fármacos que no hayan alcanzado las metas de tratamiento individualizado (D) ${ }^{1}$.

2. Insuficiencia renal crónica, dependiendo de su etapa evolutiva, insuficiencia hepática e insuficiencia cardíaca (clases funcionales grados III y IV de la American Heart Association).

3. Ante situaciones que limiten el uso de los agentes orales, tales como intolerancia, alergia, toxicidad o contraindicaciones.

\section{- Consideraciones adicionales}

Alimentación: se debe adecuar la ingesta de hidratos de carbono a la farmacocinética de las insulinas para evitar hipo o hiperglucemias, recomendando el valor calórico adecuado para atenuar el aumento de peso que pueda resultar de su uso.

Actividad física: la insulinoterapia no contraindica el ejercicio pero se debe tener precaución respecto del sitio de inyección, tipo, farmacocinética y dosis de la insulina o el análogo elegido, en relación a las características de la actividad física y el horario de su realización.

Monitoreo de la glucemia capilar: el automonitoreo glucémico es la única forma efectiva de ajustar la dosis de insulina; toda persona con DMT2 que inicia la insulinoterapia debe tener acceso a este método y a la cantidad suficiente de tiras reactivas para lograr los objetivos terapéuticos (D). La frecuencia y el momento de las mediciones se determinarán de acuerdo al esquema elegido.

\section{- Aspectos educativos}

Se deben reforzar conceptos respecto de:

1. Las técnicas de aplicación de insulina y del automonitoreo glucémico.

2. Lograr autonomía y eficiencia en la toma de decisiones.

3. Prevención, reconocimiento y manejo de episodios de hipoglucemia.

- Situaciones especiales. Existen situaciones sociales y médicas que requieren atención especial. Entre las primeras se deben considerar a los pacientes institucionalizados (cárceles, hogares de menores, instituciones geriátricas y psiquiátricas), conducción de vehículos, trabajos con horarios rotativos, etc. Entre las segundas, la amaurosis, trastornos cognitivos, alteraciones de la conducta alimentaria, etc.

- Estrategias para la insulinización. En la DMT2 se pueden utilizar todas las insulinas y análogos disponibles; todos tienen la misma eficacia en el grado de control glucémico. Una de las fortalezas de los análogos radica en la posibilidad de llegar a iguales objetivos glucémicos con menos riesgo de hipoglucemias.

- Insulinización basal. La insulinizacion basal se puede lograr utilizando insulina de acción intermedia (NPH) o los análogos lentos glargina, detemir o degludec. Es recomendable por costos iniciar con insulina NPH y progresar a análogos lentos de presentarse condiciones o situaciones que determinen su indicación, tales como la presencia de hipoglucemias sobre todo nocturnas.

Con relación al aumento de peso, observable con la insulinoterapia, existen algunos estudios no concluyentes que muestran menor ganancia con el análogo detemir en comparación con insulina $\mathrm{NPH}$ o el análogo glargina ${ }^{128,129}$. Tampoco se ha demostrado efecto beneficioso sobre el peso con el análogo degludec.

No existen contraindicaciones para el uso de ningún análogo lento en la DMT2 salvo situaciones puntuales como alergia al fármaco.

No hay evidencias de diferente eficacia entre la insulina NPH y los análogos lentos; los estudios realizados con el objetivo de registrar la equivalencia o ensayos de no inferioridad demostraron una eficacia similar, con la ventaja de 
haber presentado menor frecuencia de hipoglucemias nocturnas ${ }^{130}$. Por otro lado las evidencias relacionadas con costo-efectividad de los análogos no son concluyentes, por lo que se estima conveniente precisar las situaciones individuales en las que se los utilice ${ }^{131}$.

Respecto de la insulinización basal en las embarazadas, la misma puede realizarse de acuerdo a las evidencias, con cualquiera de los aprobados a tal efecto: la insulina NPH o el análogo detemir $(\mathbf{A})^{132}$.

- Insulinización basal-bolo (prandial). Se puede lograr con la utilización de insulina regular o de los análogos ultra rápidos lispro, aspártica o glulisina. Es recomendable por costos iniciarla con insulina regular y progresar a la utilización de análogos ultra rápidos de presentarse condiciones o situaciones que así lo ameriten, tales como hipoglucemias o necesidad de mayor flexibilidad con relación a las ingestas.

No existen contraindicaciones para el uso de análogos ultra rápidos en la DMT2, salvo situaciones especiales como alergia.

Con respecto a la insulinización prandial en las mujeres embarazadas, la misma puede realizarse de acuerdo a las evidencias con insulina regular o el análogo aspártica $(\mathbf{A})^{133}$.

- Esquema de titulación sugerido. Al iniciar la insulinizacion basal se recomienda mantener la terapia anterior, evaluando cuál de los ADs se debería reducir de dosis o suspender, teniendo especial cuidado con los insulino-secretagogos por el riesgo de hipoglucemias (A). No se recomienda la asociación de insulina con TZDs porque se acentúa el riesgo de edemas, siendo esto de particular importancia en pacientes con insuficiencia cardíaca $(\mathbf{A})^{134}$.

El inicio de la insulinoterapia basal en pacientes con DMT2 puede realizarse con una dosis de insulina NPH antes de dormir, con recaudos respecto a que el horario elegido sea siempre el mismo. En ciertos pacientes cuando la situación así lo requiera, también se puede iniciar con un análogo de acción lenta en el mismo horario (ver: "Estrategias para la insulinización").

La dosis inicial propuesta es de 0,2 UI/ $/ \mathrm{kg}$ de peso actual o directamente $10 \mathrm{UI}$ (A). Se debe medir la glucemia en ayunas todos los días para ajustar la dosis, proceso conocido como titulación ${ }^{135,136}$; el objetivo para la glucemia matinal será alcanzar un rango de entre 80 y $130 \mathrm{mg} / \mathrm{dl}$. El régimen de insulina se realizará acorde a las situaciones mencionadas previamente.
Se propone el siguiente esquema de titulación manteniendo el monitoreo glucémico matinal diario y ajustando la dosis cada tres días:

. Utilizando insulina NPH o el análogo glargina:

1. Si luego de tres controles sucesivos se registra una glucemia promedio mayor a $130 \mathrm{mg} / \mathrm{dl}$, sin haberse observado valores menores a $80 \mathrm{mg} / \mathrm{dl}$, se aumentará en $2 \mathrm{UI}$ la dosis de insulina basal nocturna.

2. Si se registran promedios glucémicos superiores a $180 \mathrm{mg} / \mathrm{dl}$, el aumento de la dosis será de $4 \mathrm{UI}^{134}$.

- Con el uso del análogo determir se sugiere la modificación de a 3 UI por vez ${ }^{137}$.

Con el uso del análogo degludec se sugiere ajustar semanalmente tomando el promedio glucémico de los últimos tres días ${ }^{138}$.

En caso de producirse hipoglucemias o glucemias de ayuno inferiores a $80 \mathrm{mg} / \mathrm{dl}$ se disminuye la insulina basal en 4 unidades o en un $10 \%$ si la dosis fuera superior a $60 \mathrm{UI}$.

. Si las glucemias se mantienen entre 80 y 130 $\mathrm{mg} / \mathrm{dl}$ se sugiere no modificar la dosis de la insulina o el análogo.

Si luego de tres meses se logra el objetivo de $\mathrm{HbA} 1 \mathrm{c}$, se continuará con el tratamiento instaurado; de no lograrse con una sola dosis basal, la elección del tipo y la estrategia para la aplicación dependerá del momento del día en el que, de acuerdo al monitoreo, se registre el mayor descontrol glucémico.

De registrarse glucemias postprandiales superiores a $160 \mathrm{mg} / \mathrm{dl}$ a las dos horas post-inicio de la ingesta, se recomienda el uso de insulina regular o análogos de acción ultra rápida de acuerdo al siguiente esquema de titulación:

. Comenzar con 4 U previo a la o las comidas que presentan glucemias superiores a $160 \mathrm{mg} / \mathrm{dl}$ y ajustar la dosis de a 1 ó 2 UI cada tres días, acorde al resultado del automonitoreo glucémico postprandial.

$\mathrm{Si}$ se detectan hiperglucemias previas a las comidas principales sin glucemias postprandiales fuera de objetivo se deberá ajustar la insulinización basal ${ }^{139}$.

Se recomienda el uso de insulinas o análogos premezclados en las siguientes situaciones:

1. Pacientes con un estilo de vida ordenado, con poca variación en el contenido y horario de las comidas, que no requieran mayor flexibilización del tratamiento.

2. Pacientes que no tienen acceso o no adhieren a un monitoreo frecuente. 


\section{CIRUGÍA BARIÁTRICA}

En DMT2 se deberá considerar esta técnica en personas con IMC $>35 \mathrm{~kg} / \mathrm{m}^{2}$, siempre que no hayan respondido al tratamiento mediante cambios en el estilo de vida (B).

Estas personas deben tener monitoreo médico estricto realizado por un equipo multidisciplinario conformado por psicólogos, Lic. en Nutrición, diabetólogo y cirujano especializado en este tipo de intervención. Se debe preparar adecuadamente al paciente para la intervención, efectuando un seguimiento a posteriori durante un período no menor a dos años.

El By Pass Gástrico en Y de Roux es la técnica de elección en pacientes con DMT2, además ha demostrado ser eficaz la manga gástrica, también llamada gastrectomía vertical o sleeve ${ }^{140}$. Luego de un estudio de metaanálisis se concluyó que el $78 \%$ de personas con DMT2 tuvo una completa resolución de su diabetes, lo cual se mantuvo durante dos años de seguimiento; los logros fueron mayores con cirugías de by pass gástrico que con restricción de la capacidad gástrica.

Adicionalmente existen evidencias que mediante la cirugía de by pass gástrico hay una reducción de la glucemia independiente y aditiva a sus efectos sobre el peso corporal.

Este tipo de cirugía es costosa y no carente de riesgos; a largo plazo se pueden presentar deficiencias de vitaminas y minerales, osteoporosis y raramente hipoglucemia. Estos riesgos pueden minimizarse por medio de un seguimiento y control a largo plazo por parte de un equipo interdisciplinario.

En cuanto a la cirugía metabólica, podría indicarse en pacientes con DM con IMC entre 30 y 34,9 y mal control de la enfermedad, después de haber implementado los mejores tratamientos farmacológicos disponibles, combinando drogas antidiabéticas orales e inyectables (ADs) e insulina ${ }^{141}$.

\section{ALGORITMO DE TRATAMIENTO PARA LA DMT2}

- Tiempos recomendados para generar ajustes en el tratamiento. Las guías de tratamiento de la DMT2 elaboradas por distintas instituciones muestran discrepancias acerca de cuándo y cómo iniciar o ajustar la terapéutica medicamentosa 142,143; otro punto de discusión es el tiempo que se debería esperar cuando no se logran los objetivos de control para asociar otros fármacos intensificando el tratamiento.
Este período deberá ser mínimo, tomando en consideración el estado clínico del paciente y las características de los diferentes agentes; el tiempo para ajustar y/o agregar medicación deberá estar dentro de los tres a seis meses con el fin de alcanzar las metas que se hayan propuesto para la $\mathrm{HbA} 1 \mathrm{c}$.

Los consensos de la ADA (American Diabetes Association) y de la EASD (European Association for Study of Diabetes) han establecido un algoritmo para el manejo de la glucemia en pacientes con DMT2 teniendo en cuenta las características de las intervenciones individuales, sus sinergias, sus costos y las particularidades propias de cada paciente ${ }^{144}$.

El objetivo del tratamiento será lograr y mantener la glucemia en niveles lo más cerca posible del rango de tolerancia normal a la glucosa, siempre que las condiciones clínicas del paciente lo justifiquen $(\mathbf{E})^{140}$.

La acción máxima de la metformina se observa a los dos meses de su prescripción, por lo que su titulación debe hacerse cada dos meses; si no se logra el objetivo metabólico se debe agregar un segundo fármaco $(\mathbf{A})^{140,145}$.

Se debe considerar una incorporación más rápida o temprana de otros agentes, incluyendo la insulina, en pacientes que persisten con hiperglucemias sintomáticas.

Las guías de la Asociación Latinoamericana de Diabetes $(A L A D)^{127}$ recomiendan iniciar el tratamiento con fármacos en toda persona con DMT2 que no haya logrado alcanzar las metas de control glucémico después de un período de tres a seis meses con cambios terapéuticos en el estilo de vida (CEV); pero si no se observa una reducción gradual de las glucemias que permita predecir que la persona alcanzará el objetivo en ese plazo, se puede adelantar el inicio del tratamiento farmacológico con metformina u otra droga en caso de intolerancia a la misma.

Se recomienda iniciar el tratamiento farmacológico desde el momento del diagnóstico, cuando el nivel de descontrol permita anticipar que los CEV no alcanzarán para reducir gradualmente las glucemias ni para alcanzar las metas en ese período.

El ajuste de la dosis de los fármacos para la DMT2 deberá hacerse en forma temprana si no se alcanza la meta de control metabólico acordada (ver más adelante).

La progresión desde la monoterapia a terapia combinada deberá hacerse en forma oportuna cuando no se alcanza la meta de control metabólico 
establecida con la dosis media de un solo fármaco en un plazo de tres a seis meses. La combinación es en general más eficaz y tiene menor riesgo de efectos secundarios que el tratamiento con dosis máximas del medicamento inicial, especialmente si son fármacos elegidos por poseer efectos complementarios con fundamentos fisiopatológicos.

Se debe considerar el tratamiento farmacológico combinado desde el principio, si las condiciones clínicas de un paciente permiten anticipar que la monoterapia no logrará las metas de buen control glucémico en un período de tres a seis meses, considerando que la combinación de fármacos producirá mayor eficacia o bien que la administración de menores dosis de cada uno mejorará la tolerabilidad o aumentará la seguridad. Algunas guías plantean aún en estas situaciones la terapéutica secuencial ${ }^{140}$.

Según las recomendaciones de la Red de Grupos de Estudio de la Diabetes en Atención Primaria de la salud (GDPS 2014, http://www.redgdps.org/), los objetivos terapéuticos deberán orientarse a un abordaje global e integral para la disminución del riesgo cardiovascular, de las complicaciones agudas y crónicas, y para mejorar la calidad de vida.

Debido al progresivo deterioro en el control de los pacientes con DM, la mayoría requiere terapias combinadas de fármacos para mantener los objetivos glucémicos en el largo plazo: a los nueve años el $75 \%$ requiere tratamiento combinado para lograr una $\mathrm{HbA} 1 \mathrm{c}<7 \%$. Las terapias de combinación tienen un efecto aditivo y reducen la $\mathrm{HbA} 1 \mathrm{c}$ más que la monoterapia; asimismo se deberá recurrir a la combinación cuando la monoterapia no sea suficiente para alcanzar los objetivos terapéuticos $64,77,146,147$.

Para ajustar el tratamiento con medicación combinada, la Sociedad Argentina de Diabetes recomienda que se consideren las siguientes pautas respecto del tiempo:

1. De tres a seis meses, hasta alcanzar el objetivo de $\mathrm{HbA} 1 \mathrm{c}$ y luego al menos cada seis meses.

2. En cualquier momento, cuando no se logran los objetivos glucémicos o ante la presencia de efectos colaterales, como hipoglucemias frecuentes y/o severas.

- Elección de la monoterapia inicial. Se recomienda la metformina como el fármaco de elección de primera línea para el tratamiento de personas con DMT2, tanto en aquellas con sobrepeso u obesidad ${ }^{17,52}$ como con peso normal pero control glucémico inadecuado ${ }^{140,141,11,12,148 .}$

El tratamiento inicial con metformina se justifi- ca por la baja tasa de eventos adversos observados con esta droga, especialmente baja respecto de la incidencia de hipoglucemias, su efecto neutro en el peso corporal, la amplia disponibilidad y su perfil de seguridad cardiovascular.

Se deberá seleccionar otro fármaco alternativo en casos de falta de tolerabilidad o contraindicación formal de la droga, en especial bajo las siguientes circunstancias:

1. Intolerancia gastrointestinal.

2. Situaciones que impliquen aumento del riesgo de acidosis láctica.

3. Creatinina sérica $>1,4 \mathrm{mg} / \mathrm{dl}$ en las mujeres $y>1,5 \mathrm{mg} / \mathrm{dl}$ en hombres.

4. $F G$ menor a $60 \mathrm{ml} /$ minuto: según las guías NICE, en pacientes que ya tomaban metformina se puede mantener igual dosis con FG entre 45 y 59 $\mathrm{ml} / \mathrm{min}$, reduciendo al $50 \%$ en pacientes con $\mathrm{FG}$ entre $30-44 \mathrm{ml} / \mathrm{min}$. Cuando se decide iniciar metformina en pacientes con FG entre $30-59 \mathrm{ml} / \mathrm{min}$, se sugiere administrar dosis medias o bajas ${ }^{149}$.

5. Insuficiencia hepática.

6. Acidosis metabólica.

7. Condiciones clínicas asociadas con hipoxemia como insuficiencia cardíaca descompensada, EPOC, etc.

8. Deshidratación.

9. Alcoholismo. Adelgazamiento, con IMC $<20 \mathrm{Kg} / \mathrm{m}^{2}$.

- Combinación de metformina con otros

fármacos. Numerosos estudios controlados aleatorizados, metaanálisis, revisiones y consensos de diversas organizaciones avalan la eficacia de la combinación de metformina con SUs, acarbosa, TZDs, meglitinidas, iDPP-4, aGLP-1, iSGLT-2 e insulina ${ }^{35,50,150}$. La elección del fármaco a asociar se realizará de acuerdo a sus propiedades, sobre todo seguridad y eficacia, la complementariedad funcional con la droga, las características del paciente que lo recibirá y otros factores como costo y facilidad para la dosificación.

Las precauciones y contraindicaciones para la asociación de fármacos con metformina son las mismas que para cada uno de ellos por separado, por ejemplo:

1. El agregado de SUs y meglitinidas puede favorecer la aparición de hipoglucemias.

2. El agregado de acarbosa puede potenciar los efectos adversos gastrointestinales y/o reducir aún más la absorción de la vitamina B12.

3. El agregado de TZDs puede inducir incremento de peso y retención hídrica. 
4. En el caso de aGLP-1 puede aparecer intolerancia gastrointestinal.

5. Los iSGLT-2 aumentan la incidencia de infecciones genitales y se ha comunicado la presentación de casos de cetoacidosis diabética ${ }^{151}$.

6. Sumada a estos dos últimos, la asociación de SUs aumenta la incidencia de hipoglucemias ${ }^{140,141 .}$

La Sociedad Argentina de Diabetes recomienda: no excluir primariamente ningún fármaco para su posible asociación con metformina; la elección se realizará de acuerdo a las características del paciente. La secuencia respecto de la combinación de fármacos deberá definirse especialmente por el riesgo de hipoglucemia, el impacto sobre el peso, la fragilidad del paciente, las comorbilidades y disponibilidad o accesibilidad al fármaco.

La Sociedad Argentina de Diabetes destaca que:

1. Debido al deterioro progresivo del control de la DM, en la mayoría de los pacientes cuando no se alcanzan los objetivos glucémicos se hace necesario combinar dos o tres fármacos.

2. Se podrá utilizar cualquier fármaco autorizado de acuerdo a las características de cada paciente, los mecanismos de acción y las fortalezas y desventajas de las diferentes drogas.

3. Se considerarán la seguridad, la tolerabilidad, la eficacia (medida por su efecto sobre la HbA1c y la glucemia), los efectos cardiovasculares y la relación costo-efectividad.

Para la elección de una terapia combinada de inicio, se tendrá en cuenta el control metabólico inicial del paciente, la presencia clínica de descompensación, la expectativa de vida y las comorbilidades.

Se podrá utilizar una combinación de tres fármacos en aquellos pacientes en quienes no se han alcanzado los objetivos de HbA1c con el uso de dos fármacos. Se ha comprobado que la terapia triple permite acceder a objetivos glucémicos adecuados cuando no se consiguen con la terapia doble.

\section{- Para elegir la mejor combinación de fármacos}

1. Se debe desestimar la asociación de drogas con similares mecanismos de acción.

2. Se debe evitar combinar fármacos cuando no representen un aumento significativo de la eficacia y/o exista una riesgosa potenciación de sus efectos secundarios.

3. En pacientes sin insulina se puede adicionar un tercer fármaco con diferente mecanismo de acción si no se alcanza el objetivo con el segundo fármaco.

4. En pacientes con insulina se debe intensificar la insulinización hasta alcanzar las metas de HbA1c.

La Tabla 4 presenta los objetivos glucémicos que la SAD considera aplicables acorde al grado funcional del paciente según los criterios tanto para A1c como para glucemia en ayunas y postprandial ${ }^{152,153,154}$.

\begin{tabular}{|l|r|c|c|}
\hline & HbA1c & GA & GPP \\
\hline Nivel general & $<7 \%$ & $<100$ & $<140$ \\
\hline Comorbilidades & $<7,5 \%$ & $<120$ & $<160$ \\
\hline Dependencia/fragilidad & $<8 \%$ & $<140$ & $<180$ \\
\hline
\end{tabular}

Tabla 4: Objetivos glucémicos.

En todas las etapas se debe reafirmar la importancia de los cambios en el estilo de vida y del automonitoreo de la glucemia.

\section{Algoritmos propuestos}

A continuación se describen dos propuestas para orientar la toma de decisiones respecto del tratamiento de la DMT2:

\begin{tabular}{|c|c|c|c|c|}
\hline \multicolumn{5}{|c|}{ CEV } \\
\hline Contraindicaciones & $\begin{array}{l}\text { Monoterapia } \\
\text { metformina u } \\
\text { otro fármaco }\end{array}$ & $\begin{array}{l}\text { Acarbosa } \\
\text { aGLP-1 } \\
\text { IDDP-4 } \\
\text { ISGLT-2 } \\
\text { SUs-MGTN } \\
\text { IZD }\end{array}$ & \multirow{7}{*}{ 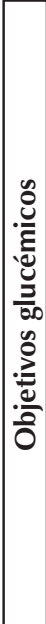 } & \multirow{2}{*}{ 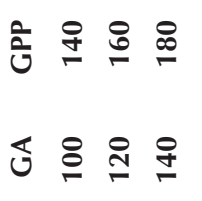 } \\
\hline Hipoglucemia & & $\begin{array}{c}\text { TZD } \\
\text { Acarbosa }\end{array}$ & & \\
\hline Peso & $\begin{array}{l}2^{\circ} \text { Medicamento } \\
\text { complementario }\end{array}$ & & & \multirow{5}{*}{ 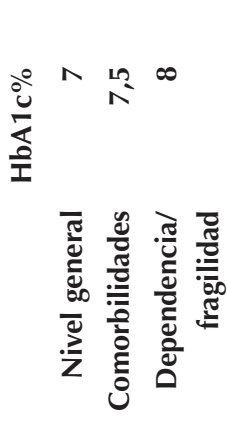 } \\
\hline & & $\begin{array}{c}\text { TZD } \\
\end{array}$ & & \\
\hline Comorbilidades/fragilidad & $\begin{array}{l}3^{\circ} \text { Medicamento } \\
\text { complementario }\end{array}$ & $\begin{array}{l}\text { Acarbosa } \\
\text { aGLP-1 } \\
\text { IDDP-4 }\end{array}$ & & \\
\hline Disponibilidad & & $\begin{array}{l}\text { ISGLT-2 } \\
\text { SUs-MGTN } \\
\text { TZD }\end{array}$ & & \\
\hline Seguridad CV & $\begin{array}{c}\text { Insulina basal + } \\
\text { metformina o } \\
\text { medicamento } \\
\text { complementario }\end{array}$ & $\begin{array}{l}\text { Acarbosa } \\
\text { aGGP-1 } \\
\text { IDLP-4 } \\
\text { ISGLI-2 } \\
\text { SMGTI } \\
\end{array}$ & & \\
\hline
\end{tabular}

Gráfico 2: Algoritmo 1. 


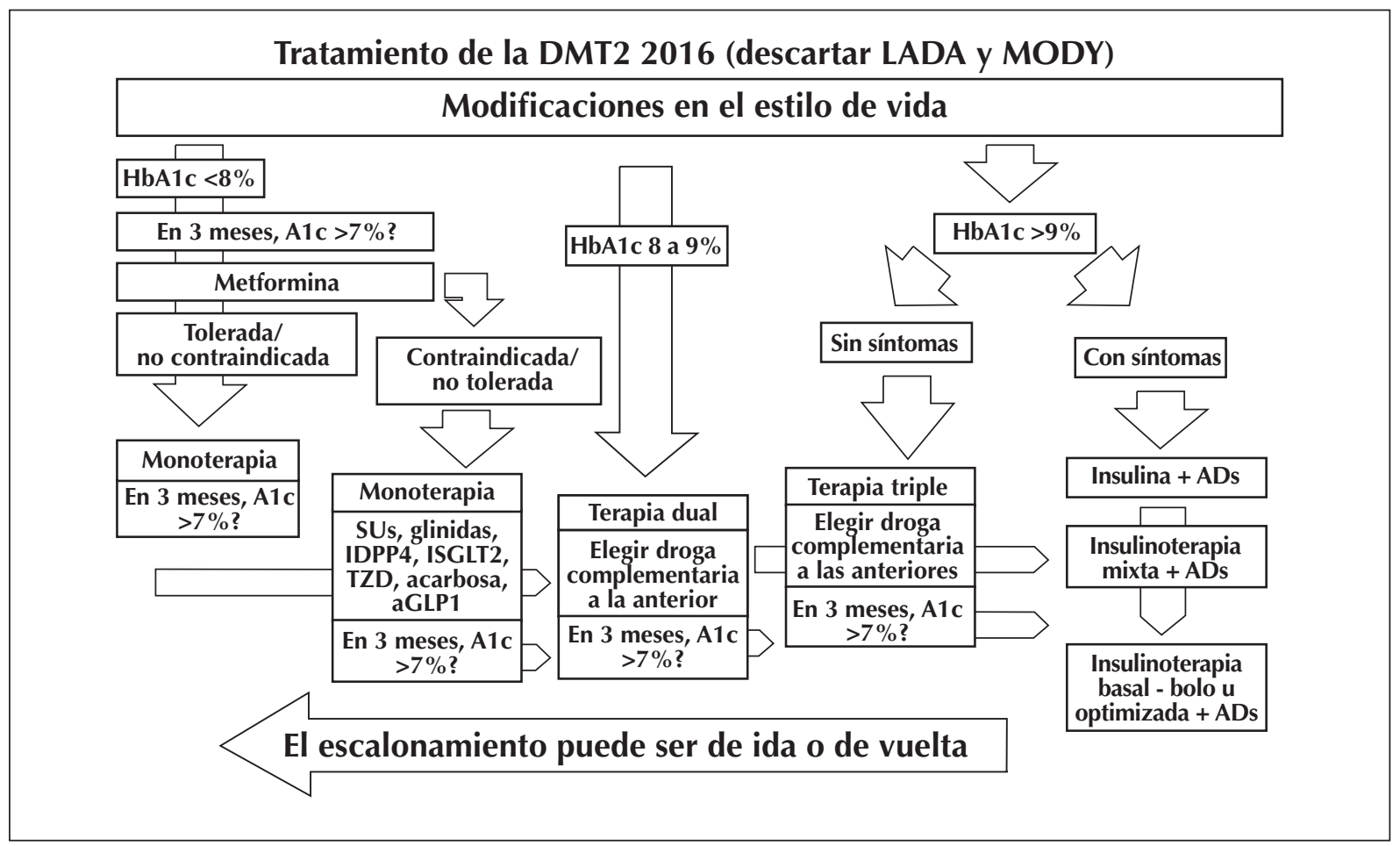

Gráfico 3: Algoritmo 2.

\begin{tabular}{|l|c|c|l|r|}
\hline \multicolumn{1}{|c|}{ Droga } & Costo & $\begin{array}{l}\text { Riesgo de } \\
\text { hipoglucemia }\end{array}$ & $\begin{array}{l}\text { Efecto en } \\
\text { el peso }\end{array}$ & $\begin{array}{l}\text { Descenso } \\
\% \text { HbA1c }\end{array}$ \\
\hline Sulfonilureas & B-M & Alto & Aumenta & $0,9-2,5$ \\
\hline Metformina & B & Bajo & Neutro & $1,5-2$ \\
\hline TZD & $\mathrm{M}$ & Bajo & Aumenta & $0,5-1,5$ \\
\hline iDPP-4 & A & Bajo & Neutro & $0,5-0,8$ \\
\hline iSGLT-2 & A & Bajo & Disminuye & $0,5-1,0$ \\
\hline aGLP-1 & MA & Bajo & Disminuye & $0,5-1,0$ \\
\hline \multicolumn{5}{|l}{$B=$ bajo / M medio / $A=$ alto / $M A=$ muy alto. } \\
\hline
\end{tabular}

Tabla 5: Tabla comparativa respecto de los aspectos más relevantes, de las drogas de uso más frecuente en nuestro medio durante su uso clínico.

Confiamos que este trabajo contribuirá a optimizar el tratamiento de las personas con DMT2 en nuestro medio.

\section{BIBLIOGRAFÍA}

1. Aschner P, Aguilar Salinas C, Aguirre L, et al. Diabetes in South and Central America: An update. Diabetes Res Clin Pract 2014; 103 (2): 238-243.

2. Han Cho N, Colagiuri S, Distiller L, Dong B, Dunning T, Gadsby R, Goel A, Munshi M, Sinclair A, Sinay I. IDF Global guideline for managing older people with type 2 diabetes. International Diabetes Federation: Brussels, Belgium; 2013.

3. IDF Diabetes Atlas, $6^{\text {th }}$ Ed., International Diabetes Federation: Brussels, Belgium; 2013.

4. Guariguata L, Whiting DR, Hambleton J, et al. Global estimates of diabetes prevalence for 2013 and projections for 2035. Diabetes Research and Clinical Practice 2014; 2:137-149.
5. Gagliardino JJ, Olivera EM. Aspecto socioeconómico de la diabetes mellitus en Argentina: diagnóstico epidemiológico. Epidemiología y atención de la salud en la Argentina. Buenos Aires: OPS, AMA. 1993 (Publicación 35).

6. Sereday M, González C, Giorgini D, De Loredo L, Braguinsky J, Cobeñas C, Libman C, Tesone C. Prevalence of diabetes, obesity, hypertension and hyperlipidemia in the central area of Argentina. Diabetes Metab 2004; 30:335-339.

7. Primera Encuesta Nacional de Factores de Riesgo. Primera Edición. Buenos Aires, Ministerio de Salud de la Nación, 2006. Disponible en: http://estadistica.cba.gov.ar/LinkClick.aspx?fileticket $=\mathrm{dSgrqG0E0}$ iY\%3D\&tabid=390\&language=es-AR.

8. Segunda Encuesta Nacional de Factores de Riesgo. Primera Edición. Buenos Aires, Ministerio de Salud de la Nación, 2011. Disponible en: http://www.msal.gob.ar/images/stories/bes/ graficos/0000000570cnt-2014-10_encuesta-nacional-factoresriesgo-2011_informe-final.pdf

9. Tercera Encuesta Nacional de Factores de Riesgo para Enfermedades No Transmisibles. Primera Edición. Buenos Aires, Ministerio de Salud de la Nación, Instituto Nacional de Estadísticas y Censos, 2015. Disponible en: http://www.msal.gob.ar/images/ stories/bes/graficos/0000000544cnt-2015_09_04_encuesta_nacional_factores_riesgo.pdf

10. PRODIABA: Programa de Prevención, Atención y Tratamiento del Paciente Diabético. Día D: Frecuencias, causas y duración de la internación de los pacientes diabéticos en hospitales públicos de la Provincia de Buenos Aires. Revista de la ALAD 1995; 3:79.

11. Gagliardino J. Evaluación preliminar de la calidad de atención de personas con diabetes en Argentina. Revista de la Sociedad Argentina de Diabetes 2001; 35:121-133.

12. The Look AHEAD Research Group. Cardiovascular effects of intensive lifestyle intervention in type 2 diabetes. N Engl J Med 2013; 369:145-154. 
13. Standards of Medical Care in Diabetes 2015. Diabetes Care 2015; 38:S1-S93.

14. Castagneto M, De Gaetano A, Mingrone G. Normalization of insulin sensitivity in the obese patient after stable weight reduction with biliopancreatic diversion. Obes Surg, 1994, 4: 161-168.

15. MarkovicTP, Campbell LV, Balasubramanian S, Jenkins AB, Fleury AC, Simons LA, Chisholm DJ. Beneficial effect on average lipid levels from energy restriction and fat loss in obese individuals with or without type 2 diabetes. Diabetes Care 1998, 21: 695-700.

16. Christiansen MP, Linfoot PA, Neese RA, Hellerstein MK. Effect of dietary energy restriction on glucose production and substrate utilization in type 2 diabetes. Diabetes 2000, 49: 1691-1699.

17. Guía de práctica clínica sobre prevención, diagnóstico y tratamiento de la diabetes mellitus tipo 2 en el primer nivel de atención. Ministerio de Salud de la Nación, 2009, 1-122. Disponible en: http://www.solesdebuenosaires.org.ar/Guias/MS-69509\%20Guia\%20Diabetes.pdf.

18. Brown SA, Upchurch S, Anding R, Winter M, Ramìrez G. Promoting weight loss in type II diabetes. Diabetes Care, 1996. 19(6): 613-24. 6 (Suppl 2): 51S-209 S.

19. Moore H, Summerbell C, Hooper L, Cruickshank K, Vyas A, Johnstone P, Ashton V, Kopelman P. Dietary advice for treatment of type 2 diabetes mellitus in adults; 2004, Pub 3, CD004097,10:1002/1465-1858.

20. Brynes AE, Mark Edwards C, Ghatei MA, Dornhorst A, Morgan LM, Bloom SR, Frost GS. A randomised four-intervention crossover study investigating the effect of carbohydrates on daytime profiles of insulin, glucose, non-esterified fatty acids and triacylglycerols in middle-aged men. Br J Nutr 2003, 89: 207-218.

21. Abbott WG, Boyce VL, Grundy SM, Howard BV. Effects of replacing saturated fat with complex carbohydrate in diets of subjects with NIDDM Diabetes Care, 1989. 12: 102-107.

22. Mensink RP, Zock PL, Kester AD, Katan MB. Effects of dietary fatty acids and carbohydrates on the ratio of serum total to HDL cholesterol and on serum lipids and apolipoproteins: a metaanalysis of 60 controlled trials. Am J Clin Nutr, 2003, 77: 1146-1155.

23. Christiansen E, Schnider S, Palmvig B, Tauber-Lassen E, Pedersen $\mathrm{O}$. Intake of a diet high in trans monounsaturated fatty acids or saturated fatty acids: effects on postprandial insulinemia and glycemia in obese patients with NIDDM. Diabetes Care 1997; 20: 881-887.

24. Riccardi G, Rivellese A, Pacioni D, Genovese S, Mastranzo P. Separate influence of dietary carbohydrate and fibre on the metabolic control in diabetes. Diabetologia 1984, 26: 116-121.

25. Lousley SE, Jones DB, Slaughter P, Carter RD, Jelfs R, Mann JI. High carbohydrate-high fibre diets in poorly controlled diabetes. Diabet Med 1984, 1: 21-25.

26. Yeh GY, Eisenberg DM, KaptchukTJ, Phillips RS. Systematic review of herbs and dietary supplements for glycemic control in diabetes. Diabetes Care 2003, 26: 1277-1294.

27. Althuis MD, Jordan NE, Ludington EA, Wittes JT. Glucose and insulin responses to dietary chromium supplements: a metaanalysis. Am J Clin Nutr 2002, 76: 148-155.

28. Ekinci El, Clarke S, Thomas MC, Moran JL, Cheong K, Macisaac RJ, Jerums G. Dietary salt intake and mortality in patients with type 2 diabetes. Diabetes Care 2011, 34: 703-709.

29. Garg A. High-monounsaturated-fat diets for patients with diabetes mellitus: a meta-analysis. Am J Clin Nutr 1998; 67 (Suppl 1): 577-582.

30. Alam S, Johnson AG. A meta-analysis of randomised controlled trials (RCT) among healthy normotensive and essential hypertensive elderly patients to determine the effect of high salt $(\mathrm{NaCl})$ diet on blood pressure. J Hum Hypertens 1999; 13: 367-374.
31. Hooper L, Bartlett C, Davey Smith G, Ebrahim S. Systematic review of long term effects of advice to reduce dietary salt in adults. BMJ 2002; 325 (7365): 628-637.

32. Samaha FF, Iqbal N, Seshadri P, Kathryn L, Chicano KL, Daily DA, McGrory J, WilliamsT, William M, Gracely EJ, Stern L. A low carbohydrate as compared with a low-fat diet in severe obesity. $\mathrm{N}$ Engl J Med 2003, 348: 2074-2081.

33. Tsihlias EB, Gibbs AL, McBurney MI, Wolever TM. Comparison of high and lowglycemicindex breakfast cereals with monounsaturated fat in the long-term dietary management of type 2 diabetes. Am J Clin Nutr, 2000. 72: 439-449.

34. Farmer A, Montori V, Dinneen S, Clar C. Fish oil in people with type 2 diabetes mellitus. Cochrane Database Syst Rev, 2001: CD003205.

35. Canadian Diabetes Association. Clinical Practice Guidelines 2008, 1-201. Disponible en: http://www.diabetes.ca/for-professionals/resources/2008-cpg.

36. Gill JM, Cooper AR. Physical activity and prevention of type 2 diabetes mellitus. Sports Med. 2008; 38: 807-814.

37. Cox KL, Burke V, Morton AR, Beilin LJ, Puddey IB. Independent and additive effects of energy restriction and exercise on glucose and insulin concentrations in sedentary overweight men. Am $\mathrm{J}$ Clin Nutr 004; 80308-80316.

38. Miller WC, Koceja DM, Hamilton EJ. A meta-analysis of the past 25 years of weight loss research using diet, exercise or diet plus exercise intervention. Int J Obes Relat Metab Disord. 1997; 21: 941-947.

39. Lee IM, Djoussé L, Sesso HD, Wang L, Buring JE. Physical activity and weight gain prevention. JAMA. 2010; 303: 1173-1179.

40. Pan XR, Li GW, Hu YH, Wang JX, Yang WY, An ZX, Hu ZX, Lin J, Xiao JZ, Cao HB, Liu PA, Jiang XG, Jiang YY, Wang JP, Zheng $H$, Zhang $\mathrm{H}$, Bennett $\mathrm{PH}$, Howard BV. Effects of diet and exercise in preventing NIDDM in people with impaired glucose tolerance. The Da Qing IGT and Diabetes Study. Diabetes Care 1997; 20: 537-544.

41. Uusitupa M, Louheranta A, Lindström J, ValleT, Sundvall J, Eriksson J, Tuomilehto J. The Finnish Diabetes Prevention Study. Br J Nutr 2000; 83 Suppl 1: S 137-42.

42. Lindström J, Peltonen M, Eriksson JG, Aunola S, Hämäläinen H, llanne-Parikka P, Keinänen-Kiukaanniemi S, Uusitupa M,Tuomilehto J. Finnish Diabetes Prevention Study (DPS) Group. Determinants for the effectiveness of lifestyle intervention in the Finnish Diabetes Prevention Study. Diabetes Care 2008; 31: 857-862.

43. No authors listed, Diabetes Prevention Program Group. Diabetes Care 1999; 23:623-634.

44. Boulé NG, Kenny GP, Haddad E, Wells GA, Sigal RJ. Metaanalysis of the effect of structured exercise training on cardiorespiratory fitness in type 2 diabetes mellitus. Diabetologia. 2003; 46: 1071-1081.

45. Thomas DE, Elliott EJ, Naughton GA. Exercise for type 2 diabetes mellitus. Cochrane Database Syst Rev. 2006; 3: CD002968.

46. Kelley GA, Kelley KS. Effects of aerobic exercise on lipids and lipoproteins in adults with type 2 diabetes: a meta-analysis of randomized-controlled trials. Public Health. 2007; 121: 643-655.

47. Kelley DE, Goodpaster BH. Effects of exercise on glucose homeostasis in type 2 diabetes mellitus. Med Sci Sports Exerc. 2001; 33 (6 Suppl): S 495-501.

48. Whelton SP, Chin A, Xin X, He J. Effect of aerobic exercise on blood pressure: a metaanalysis of randomized, controlled trials. Ann Intern Med. 2002; 136: 493-503.

49. Ekelund U, Ward HA, NoratT, Luan J, May E, Weiderpass E, Sharp SS, et al. Physical activity and all-cause mortality across levels of overall and abdominal adiposity in European men and women: the European Prospective Investigation into Cancer and Nutrition Study (EPIC). Am J Clin Nutr 2015 doi: 10.3945/ajcn.114.100065. 
50. Hundal RS, Krssak M, Dufour S, Laurent D, Lebon V, Chandramouli V, Inzucchi SE, Schumann WC, Petersen KF, Landau BR, Shulman $\mathrm{GI}$. Mechanism by which metformin reduces glucose production in type 2 diabetes. Diabetes 2000, 49: 2063-2069.

51. Foretz M, Guigas B, Bertrand L, Pollak M, Viollet B. Metformin: from mechanisms of action to therapies. Cell Metab. 2014; 20 (6): 953-66.

52. Bailey C, Turner R. Metformin, review article. New Engl J Med 1996, 334: 574-579.

53. Bloomgarden Z. Approaches to treatment of type 2 diabetes. Diabetes Care, 2008; 31: 1697-1703.

54. Cusi K, De Fronzo R. Metformin: a review of its metabolic effects. Diabetes Rev 1998, 6: 89131.

55. De Fronzo R, et al. Multicenter Metformin Study Group. N Engl J Med 1995, 333: 541-549.

56. Kothny W, Foley J, Kozlovski P, Shao Q, Gallwitz B, Lukashevich $\mathrm{V}$. Improved glycaemic control with vildagliptin added to insulin, with or without metformin, in patients with type 2 diabetes meIlitus. Diabetes, obesity and metabolism 2013, 15: 252-257.

57. Brackett C. Clarifying metformin's role and risks in liver dysfunction. Pharm D J Am Pharm Assoc 2010; 50: 407-410.

58. Herman W, Hoerger T, Brandle M, Hicks K, Sorensen S, Zhang $\mathrm{P}$. The cost-effectiveness of lifestyle modification or metformin in preventing type 2 diabetes in adults with impaired glucose tolerance. Ann Intern Med 2005, 142: 323-332.

59. Hundal R, Inzucchi SE. Metformin: new concepts, new uses. Drugs 2003,63: 1879-1894.

60. Iki-Jarvinen H. Metformin prevents weight gain by reducing dietary intake during insulin therapy in patients with type 2 diabetes mellitus. Drugs 1999, Suppl 1: 53-54.

61. Johanssen K. Efficacy of metformin in the treatment of NIDDM, meta-analysis. Diabetes Care 1999, 22: 33-37.

62. Chiquette $E$, Ramirez G, DeFronzo R. A meta-analysis comparing the effect of thiazolidinediones on cardiovascular risk factors. Arch Intern Med. 2004; 164: 2097-2104.

63. Lebovitz HE, Dole JF, Patwardhan R, Rappaport EB, Freed MI. Rosiglitazone monotherapy is effective in patients with type 2 diabetes. J Clin Endocrinol Metab 2001; 86: 280-288.

64. Kahn SE, Haffner SM, Heise MA, Herman WH, Holman RR, Jones NP, Kravitz BG, Lachin JM, O'Neill MC, Zinman B, Viberti G; ADOPT Study Group. Glycemic durability of rosiglitazone, metformin, or glyburide monotherapy. N Engl J Med 2006, 355: 2427-2443.

65. Dormandy JA, Charbonnel B, Eckland EJA, Erdmann E, MassiBenedetti M, Moules IK, et al. Secondary prevention of macrovascular events in patients with type 2 diabetes: a randomized trial of pioglitazone: the PROactive Study (PROspective pioglitAzone Clinical Trial In macro Vascular Events). Lancet 2005, 366: 1279-1289.

66. Nissen S, Wolski N. Effect of rosiglitazone on the risk of myocardial infarction and death from cardiovascular causes. $\mathrm{N}$ Engl J Med 2007; 356: 2457-2471.

67. Home P, Pocock SJ, Beck-Nielsen H, Curtis PS, Gomis R, Hanefeld M, Jones NP, et al. RECORD Study Team. Rosiglitazone evaluated for cardiovascular outcomes in oral agent combination therapy for type 2 diabetes. A multicentre, randomised, openlabel trial.Lancet. 2009 20; 373: 2125-2135.

68. Gerstein HC, Yusuf S, Bosch J, Pogue J, Sheridan P, Dinccag N, et al. Effect of rosiglitazone on the frequency of diabetes in patients with impaired glucose tolerance or impaired fasting glucose: a randomised controlled trial. Lancet. 2006; 368: 1096-1105.
69. AACE Diabetes Mellitus Clinical Practice Guidelines Task Force American Association of Clinical Endocrinologists medical guidelines for clinical practice for the management of diabetes meIlitus. Endocr Pract. 2007; 13 (Suppl 1): 3-68.

70. Completion of the Post-Marketing Commitment to Submit Data to the FDA. First Word Pharma, 28, August 2014. Disponible en: http://www.firstwordpharma.com/node/1232261\#axzz3BIGF2Jfp.

71. Schernthaner G, Currie CJ, Schernthaner GH. Do we still need pioglitazone for the treatment of type 2 diabetes? Diabetes Care 2013; 36: 155-161.

72. Nathan DM, Buse JB, Davidson MB, et al. Medical management of hyperglycemia in type 2 diabetes: a consensus algorithm for the initiation and adjustment of therapy. A consensus statement of the American Diabetes Association and the European Association for the Study of Diabetes. Diabetes Care. 2009; 32: 193-203.

73. Cook CJ, Girman CJ, Stein PP, Alexander CM, Holman RR. Glycemic control continues to deteriorate after sulfonylureas are added to metformin in patients with type 2 diabetes. Diabetes Care 2005: 28: 995-1000.

74. Saad MF, Kahn SE, Nelson RG, Pettitt DJ, Knowler WC, Schwartz MW, et al. Disproportionately elevated proinsulin in Pima Indians with noninsulin-dependent diabetes mellitus. J Clin Endocrinol Metab. 1990, 70: 1247-1253.

75. The UKPDS study group. Intensive blood glucose control with sulphonyureas or insulin compared with conventional treatment and risk of complications in patients with type 2 diabetes (UKPDS 33) Lancet 1998; 353: 837-853.

76. Schopman JE, Simon AC, Hoefnagel SJ, Hoekstra JB, Scholten RJ, Holleman F. The incidence of mild and severe hypoglycaemia in patients with type 2 diabetes mellitus treated with sulfonylureas: a systematic review and meta-analysis. Diabetes Metab Res Rev. 2014; 30 (1): 11-22

77. Simpson SH, Majumdar SR, Tsuyuki RT, Eurich DT, Johnson JA. Dose response relation between sulfonylureas drugs and mortality in type 2 diabetes. CMAJ 2006: 169-174.

78. Rosenstock J, Hassman DR, Madder RD, Brazinsky S, Farrell J Khutoryansky N, Hale P. Repaglinide versus nateglinide monotherapy: a randomized, multicenter study. Diabetes Care 2004, 27: 1265-1270.

79. Gerich J, Raskin P, Jean-Louis L, Purkayastha D, Baron MA. PRESERVE-beta: two year efficacy and safety of initial combination therapy with nateglinide or glyburide plus metformin. Diabetes Care 2005, 28: 2093-2099.

80. Nathan D. Finding new treatments for diabetes: How many, how fast, how good. N Engl J Med: 2007, 356: 5: 437-440.

81. Ruiz M, Matrone A, Alvariñas J, Burlando G, Tesone P, Jorge A. Estudio multicéntrico para determinar eficacia y tolerancia de acarbosa en pacientes con diabetes no insulinodependiente. Prensa Med Arg. 1996: 83: 392-398.

82. Chiasson JL, Gomis R, Hanefeld M, Josse RG, Karasik A, Laakso $M$, and The STOP-NIDDM Trial Research Group. The STOP-NIDDM Trial: An international study on the efficacy of an $\alpha$-glucosidase inhibitor to prevent type 2 diabetes in a population with impaired glucose tolerance: rationale, design, and preliminary screening data. Diabetes Care, 1998, 21: 1720-1725.

83. Klonoff D, Busse J, Nielsen L, Guan Xuenson, Bowlus Ch, Holcombe J, Wintle M, Maggs D. Exenatide effects on diabetes, obesity, cardiovascular risk factors and hepatic biomarkers in patients with type 2 diabetes treated for at least 3 years. Curr Med Res Opinion 2008, 24: 275-286.

84. Van del Koppel S, Choe E, Sweet B. Managed care perspective on three new agents for type 2 diabetes. J Manag Care Pharm 2008,14: 363-380. 
85. Farilla L, Bulotta A, Hirshberg B, Li Calzi S, Khoury N, Noushmehr H, Bertolotto C, Di Mario U, Harlan DM, Perfetti R. Glucagon-like peptide 1 inhibits cell apoptosis and improves glucose responsiveness of freshly isolated human islets. Endocrinology 2003, 144: 5149-5158.

86. Prospecto: Información para el usuario. Victoza $6 \mathrm{mg} / \mathrm{ml}$ solución inyectable en pluma precargada. Fecha de la última revisión: 03/2015.

87. Dore D, Seeger J, Chan A. Use of a claims-based active drug safety surveillance system to assess the risk of acute pancreatitis with exenatide or sitagliptin compared to metformin or glyburide. Curr Med Res Opinion 2009, 25: 1019-1027.

88. Zinman B, Gerich J, Buse J, et al. Efficacy and safety of the human glucagon-like peptide-1 analog liraglutide in combination with metformin and thiazolidinedione in patients with type 2 diabetes (LEAD-4 Met+TZD). Diabetes Care 2009, 32: 1224-1230.

89. Pfeffer MA, Claggett B, Diaz R, Dickstein K, Gerstein HC, et al. Lixisenatide in patients with type 2 diabetes and acute coronary syndrome. N Engl J Med 2015; 373: 2247-2257, 2015.

90. Marso SP, Daniels GH, Brown-Frandsen K, et al. For the LEADER Steering Committee on behalf of the LEADERTrial Investigators. June 13, 2016 DOI: 10.1056/NEJMoa1603827).

91. Girad J. The incretins from the concept to their use in the treatment of type 2 diabetes. Part A: Incretins. Diabetes Metab 2008; 34: 550-559.

92. Hvidberg A, et al. Efect of glucagon-like peptide-1 (proglucagon 78-107 amide) on hepatic glucose production in healthy man. Metabolism 1994; 43: 104-108.

93. Nauk M. Effects of subcutaneous glucagon-like peptide 1 (GLP1 - 7-36 amide) in patients with NIDDM. Diabetologia 1996; 29 : 1546-52.

94. Herman GA, et al. Effect of a single oral dose of sitagliptin, a dipeptidyl peptidase.4 inhibitor, on incretin and plasma glucose levels after an oral glucose tolerance test in patients with type 2 diabetes. J Clin Endocrinol Metab 2006, 91: 4612-4619.

95. Arechavaleta R. Efficacy and safety of treatment with sitagliptin or glimepiride in patients with type 2 diabetes inadequately controlled on metformin monotherapy: a randomized, double-blind, non inferiority trial. Diabetes Obes Metab 2011; 13: 160-168.

96. Scheen AJ, et al. Efficacy and safety of saxagliptin in combination with metformin compared with sitagliptin in combination with metformin in adult patients with type 2 diabetes mellitus. Diabetes Metab Res Rev 2010; 26: 540.

97. Valensi $P$, et al.Treatment maintenance duration of dual therapy with metformin and sitagliptin in type 2 diabetes. The ODYSSEE observational Study. Diabetes Metab 2015; 41: 231-238.

98. Herman W, Johnson J, et al. Efficacy and safety of initial combination theraphy with sitagliptin and metformin in patients with type 2 diabetes: a 54-week study. Curr Med Opin 2009; 25: 569-583.

99. Herman W, et al. Safety and tolerability of sitagliptin in clinical studies: a pooled analysis of data from 10246 patients with type 2 diabetes. BMC Endocr Disord 2010; 22: 10-17.

100. Richter B, Bandeira-Echtler E, et al. Dipeptidylpeptidase 4 (DPP4) inhibitors for type 2 diabetes mellitus. Cochrane Data base Syst, 2008. Rev 2: CD006739.

101. Egan A, Blind $E$, et al. Pancreatic safety of incretin-based FDA and EMA assessment. N Eng J Med 2014; 27: 370-379.

102. SAVOR-TIMI 53. Saxagliptin and cardiovascular outcomes in patients with type 2 diabetes mellitus. N Eng J Med 2013; 3: 13171326.

103. TECOS Study group. Effect of sitagliptin on cardiovascular outcomes in type 2 diabetes (TECOS). N Engl J Med 2015, 373 (3): 232-242.
104. Kishimoto M. Teneligliptin: a DPP-4 inhibitor for the treatment of type 2 diabetes. Diabetes Metab Syndr Obes 2013; 6: 187-195.

105. Bailey T. Options for combination therapy in type 2 diabetes: comparison of the ADA-EASD position statement and AACEACE algorithm. Am J Med 2013;126: S10-20.

106. Vivian EM. Dapagliflozin: a new sodium-glucose cotransporter 2 inhibitor for treatment of type 2 diabetes. Am J Health-Syst Pharm. 2015; 72: 361-372.

107. Skrtic M, Cherney DZI. Sodium-glucose cotransporter-2 inhibition and the potential for renal protection in diabetic nephropathy. Curr Opin Nephrol Hypertens 2015; 24: 96-103.

108. Bailey CJ, Gross JL, Hennicken D, et al. Dapagliflozin add-on to metformin in type 2 diabetes inadequately controlled with metformin: a randomized, double blind, placebo-controlled 102week trial. BMC Med. 2013; 11-43.

109. Abdul-Ghani M. Where does combination therapy with an SGLT2 inhibitor plus a DPP-4 inhibitor fit in the management of type 2 diabetes? Diabetes Care 2015; 38: 373-375.

110. Rosenstock J, Hansen L, Zee P, et al. Dual add-on therapy in type 2 diabetes poorly controlled with metformin monotherapy: a randomized double-blind trial of saxagliptin plus dapagliflozin addition versus single addition of saxagliptin or dapagliflozin to metformin. Diabetes Care 2015;38: 376-383.

111. Wilding JP, Woo V, Rohwedder K, et al. Dapagliflozin in patients with type 2 diabetes receiving high doses of insulin: efficacy and safety over two years. Diabetes Obes Metab. 2014; 16: 124-136.

112. Ferrannini E, Ramos SJ, Salsali A, et al. Dapagliflozin monotherapy in type 2 diabetic patients with inadequate glycemic control by diet and exercise: a randomized, double-blind, placebo controlled, Phase 3 trial. Diabetes Care 2010; 33: 2217-24.

113. Kohan DE, Fioretto $P$, Tang $W$, et al. Long-term study of patients with type 2 diabetes and moderate renal impairment shows that dapagliflozin reduces weight and blood pressure but does not improve glycemic control. Kidney Int 2014; 85: 962-71.

114. Bolinder J, Ljunggren O, Kullberg J, et al. Effects of dapagliflozin on body weight, total fat mass, and regional adipose tissue distribution in patients with type 2 diabetes mellitus with inadequate glycemic control on metformin. J Clin Endocrinol Metab 2012; 97: 1020-31.

115. Majewski C, Bakris GL. Blood pressure reduction: an added benefit of sodium-glucose cotransporter 2 inhibitors in patients with type 2 diabetes. Diabetes Care 2015; 38: 429-430.

116. Foote C, Perkovic V, Neal B. Effects of SGLT2 inhibitors on cardiovascular outcomes. Diab Vasc Dis Res 2012; 9: 117-123.

117. Inzucchi SE, Zinman B, Wanner C. SGLT-2 inhibitors and cardiovascular risk: proposed pathways and review of ongoing outcome trials. Diabetes \& Vascular Disease Research 2015; 12: 90-100.

118. Zinman B, Wanner D, Lachin JM, Fitchett D, Bluhmki E, Hantel S, et al. For the EMPA-REG OUTCOME Investigators. Empagliflozin, cardiovascular outcomes, and mortality in type 2 diabetes. NEJM DOI: 10.1056/NEJMoa1504720.

119. Ferrannini E, Muscelli E, Frascerra S, et al. Metabolic response to sodium-glucose cotransporter 2 inhibition in type 2 diabetic patients. J Clin Invest 2014; 124: 499-508.

120. Johnsson KM, Ptaszynska A, Schmitz B, et al. Urinary tract infections in patients with diabetes treated with dapagliflozin. $J$ Diabetes Complications 2013; 27: 473-478.

121. Johnsson KM, Ptaszynska A, Schmitz B, et al. Vulvovaginitis and balanitis in patients with diabetes treated with dapagliflozin. J Diabetes Complications 2013; 27: 479-484.

122. Geerlings S, Fonseca V, Castro-Diaz D, et al. Genital and urinary tract infections in diabetes: impact of pharmacologically-induced glucosuria. Diabetes Res Clin Pract 2014; 103: 373-381. 
123. Yanovski SZ, Yanovski JA. Long-term drug treatment for obesity: a systematic and clinical review. JAMA 2014; 311(1)74-86.

124. NIH, Biblioteca Nacional de Medicina de los EE.UU. MedlinePlus. Información de salud para usted. Disponible en: https://www.nlm. nih.gov/medlineplus/spanish/druginfo/meds/a601244-es.html

125. Cavaliere H, Florianol, Medeiros-Neto G. Gastrointestinal side effects of orlistat maybe prevented by concomitant prescription of natural fibers (psyllium mucilloid). Int J Obes Relat Metab Disord. 2001;25(7):1095-1099.

126. U.S. Food and Drug Administration, Questions and answers: orlistat and severe liver injury. Disponible en: http://www.fda. gov/drugs/drugsafety/postmarketdrugsafetyinformationforpatientsandproviders/ucm213040.htm

127. Guías $A L A D$ de diagnóstico, control y tratamiento de la diabetes mellitus tipo 2. Revista de la ALAD, 2006, 14: 129-134.

128. Hermansen K, Davies M, DerezinskiT, Martinez Ravn G, Clauson P, Home P. A 26-week, randomized, parallel, treat-to-target trial comparing insulin detemir with NPH insulin as add-on therapy to oral glucose-lowering drugs in insulin-naive people with type 2 diabetes. Diabetes Care. 2006; 29: 1269-1274.

129. Fritsche A, Haring $\mathrm{H}$. At last, a weight neutral insulin? Int J Obes Relat Metab Disord 2004; 28 (Suppl 2): S 41-46.

130. Horvath K, Jeitler K, Berghold A, Ebrahim SH, Gratzer TW, Plank J, Kaiser T, Pieber TR, Siebenhofer A. Long-acting insulin analogues versus NPH insulin (human isophane insulin) for type 2 diabetes mellitus. Cochrane Database of Systematic Reviews. 2007, Issue 2 Art. No CD005613. DOI: 10.1002/14651858. CD005613.pub3.

131. Chris G, Cameron MS, Heather A, Bennett B. Cost-effectiveness of insulin analogues for diabetes mellitus, CMAJ 2009; 180 (4): 400-407.

132. Mathiesen ER, Hod M, Ivanisevic M, Duran Garcia S, Brøndsted $L$, Jovanovic $L$, et al. Maternal efficacy and safety outcomes in a randomized, controlled trial comparing insulin detemir with NPH insulin in 310 pregnant women with type 1 diabetes. Diabetes Care 2012; 35: 2012-2017.

133. Mathiesen ER. Maternal glycemic control and hypoglycemia in type 1 diabetic pregnancy. A randomized trial of insulin aspart versus human insulin in 322 pregnant women. Diabetes Care 2007; 30: 771-776.

134. Nathan DM, Buse JB, Davidson MB, Ferrannini E, Holman RR, Sherwin R, Zinman B. Management of hyperglycemia in type 2 diabetes: a consensus algorithm for the initiation and adjustment of therapy: update regarding thiazolidinediones: a consensus statement from the American Diabetes Association and the European Association for the Study of Diabetes. Diabetes Care 2008; 31: 173-175.

135. Rosenstock J, Schwartz SL, Clark CM Jr, Park GD, Donley DW, Edwards MB. Basal insulin therapy in type 2 diabetes: 28-week comparison of insulin glargine (HOE 901) and NPH insulin. Diabetes Care 2001; 24:631-636.

136. Riddle MC, Rosenstock J, Gerich J. Insulin Glargine 4002 Study Investigators. treat-to-target trial: randomized addition of glargine or human NPH insulin to oral therapy of type 2 diabetic patients. Diabetes Care 2003; 26: 3080-3086.

137. Blonde L, Merilainen M, Karwe V, Raskin P. For the TITRATE Study Group. Patient-directed titration for achieving glycaemic goals using a once-daily basal insulin analogue: an assessment of two different fasting plasma glucose targets. TheTITRATE study. Diabetes Obesity \& Metabolism 2009; 11: 623-631.

138. Philis-Tsimikas A, Brod M, Niemeyer M, Ocampo Francisco AM, Rothman J. Insulin degludec once-daily in type 2 diabetes: simple or step-wise titration (BEGIN: once simple use). Adv Ther 2013; 30: 607-22.
139. Nathan DM, Buse JB, Davidson MB, Heine RJ, Holman RR Sherwin R, Zinman B; Professional Practice Committee, American Diabetes Association; European Association for the Study of Diabetes. Management of hyperglycaemia in type 2 diabetes: a consensus algorithm for the initiation and adjustment of therapy. A consensus statement from the American Diabetes Association and the European Association for the Study of Diabetes. Diabetes Care. 2006; 29: 1963-1972.

140. Schauer P, Bhatt DL, Kirwan JP, Wolski K, Kashyap SR. Bariatric surgery versus intensive medical therapy for diabetes-3-year outcomes. N Engl J Med 2014; 370:2002-2013.

141. Sociedad Argentina de Diabetes (SAD), Sociedad Argentina de Nutrición (SAN), Sociedad Argentina de Cirugía de la Obesidad (SACO). Consenso Argentino de Cirugía Metabólica. Revista de la Sociedad Argentina de Diabetes, Vol. 49, №3, 2015: 95-110.

142. Clinical practice guidelines for treatment of diabetes mellitus. Expert Committee of the Canadian Diabetes Advisory Board. CMAJ. 1992; 147: 697-712.

143. American Diabetes Association. Standars of medical care in diabetes, 2008, 1-43 http://care.diabetesjournals.org/content/31/ Supplement_1/S12.full

144. Inzucchi SE, Bergenstal RM, Buse JB, Diamant M, Ferrannini E, Nauck M, Peters AL, Tsapas A, Wender R, Matthews DR. Management of hyperglycemia in type 2 diabetes, 2015: a patient centered approach update to a position statement of the American Diabetes Association and the European Association for the Study of Diabetes. Diabetes Care 2015; 38: 140-149.

145. AACE/ACE Guidelines. American Association of Clinical Endocrinologist and American College of Endocrinology- Clinical Practice Guidelines for Developing a Diabetes Mellitus Comprenhesive Care Plan 2015. Endocrine Practice, Vol. 21 (suppl 1).

146. Rosenstock J, Hassman DR, Madder RD, Brazinsky S, Farrell J, Khutoryansky N, Hale PM. Repaglinide versus nateglinide monotherapy: a randomized, multicenter study. Diabetes Care 2004, 27: 1265-1270.

147. Gerich J, Raskin P, Jean-Louis L, Purkayastha D, Baron MA. PRESERVE-beta: two year efficacy and safety of initial combination therapy with nateglinide or glyburide plus metformin. Diabetes Care 2005, 28: 2093-2099.

148. Hundal R, Inzucchi SE. Metformin: new concepts, new uses. Drugs 2003, 63: 1879-1894.

149. Nice guidelines (NG28), type 2 diabetes in adults: management, 2015. Disponible en: https://www.nice.org.uk/guidance/ng28/ chapter/1-Recommendations.

150. Johanssen K. Efficacy of metformin in the treatment of NIDDM. Meta-analysis. Diabetes Care 1999, 22: 33-37.

151. FDA Drug Safety Communication: FDA warns that SGLT2 inhibitors for diabetes may result in a serious condition of too much acid in the blood, 2015. Disponible en: http://www.fda gov/Drugs/DrugSafety/ucm446845.htm /European Medicines Agency confirms recommendations to minimise ketoacidosis risk with SGLT2 inhibitors for diabetes, 2015. http://www. ema.europa.eu/ema/index.jsp?curl=pages/medicines/human/ referrals/SGLT2_inhibitors/human_referral_prac_000052. jsp\&mid=WC0b01ac05805c516f.

152. American Diabetes Association. Standards of Medical Care in Diabetes 2016. Diabetes Care 2016;39 (Suppl. 1):S1-S109.

153. Sociedad Argentina de Diabetes. Guía del tratamiento de la diabetes mellitus tipo 2 año 2010; www.diabetes.org.ar/wp-content/ uploads/2015/02/2010_10_SAD_Guia_del_Tratamiento_de_la DM2.pdf.

154. International Diabetes Federation. Managing Older People With Type 2 Diabetes. Global Guideline 2013; www.idf. org/sites/default/files/IDF-Guideline-for-older-people-T2D.pdf. 